\title{
Interannual evolution of (sub)mesoscale dynamics in the Bay of Biscay
}

\author{
Guillaume Charria $^{1}$, Sébastien Theetten ${ }^{1}$, Frédéric Vandermeirsch ${ }^{1}$, Özge Yelekçi ${ }^{1}$, and Nicole Audiffren ${ }^{2}$ \\ ${ }^{1}$ Ifremer, Univ. Brest, CNRS, IRD, Laboratoire d'Océanographie Physique et Spatiale (LOPS), IUEM, 29280 Brest, France \\ ${ }^{2}$ CINES, 34090 Montpellier, France \\ Correspondence to: Guillaume Charria (guillaume.charria@ifremer.fr)
}

Received: 29 November 2016 - Discussion started: 26 January 2017

Revised: 6 August 2017 - Accepted: 8 August 2017 - Published: 25 September 2017

\begin{abstract}
In the north-east Atlantic Ocean, the Bay of Biscay is an intersection between a coastal constrained dynamics (wide continental shelf and shelf break regions) and an eastern boundary circulation system. In this framework, the eddy kinetic energy is 1 order of magnitude lower than in western boundary systems. To explore this coastal complex system, a high-resolution ( $1 \mathrm{~km}, 100$ vertical sigma layers) model experiment including tidal dynamics over a period of 10 years (2001-2010) has been implemented. The ability of the numerical environment to reproduce main patterns over interannual scales is demonstrated. Based on this experiment, the features of the (sub)mesoscale processes are described in the deep part of the region (i.e. abyssal plain and continental slope). A system with the development of mixed layer instabilities at the end of winter is highlighted. Beyond confirming an observed behaviour of seasonal (sub)mesoscale activity in other regions, the simulated period allows exploring the interannual variability of these structures. A relationship between the winter maximum of mixed layer depth and the intensity of (sub)mesoscale related activity (vertical velocity, relative vorticity) is revealed and can be explained by largescale atmospheric forcings (e.g. the cold winter in 2005). The first submesoscale-permitting exploration of this 3-D coastal system shows the importance of (sub)mesoscale activity in this region with its evolution implying a potentially significant impact on vertical and horizontal mixing.
\end{abstract}

\section{Introduction}

As a semi-enclosed region, the Bay of Biscay (Fig. 1) can be divided in three dynamical regimes: the circulation over the continental shelf, the transition region above the shelf break and the open ocean part. Our understanding of the general associated circulation in the Bay of Biscay has been progressively refined following the available observations and the improvement of numerical models. The first review by Koutsikopoulos and Le Cann (1996) introduced the general circulation patterns with a poleward circulation over the continental shelf, a poleward slope current and a general anticyclonic circulation in the open ocean. This general scheme has been detailed with new datasets from drifters in van Aken (2002), Charria et al. (2013) and Porter et al. (2016); from acoustic Doppler current profiler (ADCP) moorings in Batifoulier et al. (2012), Le Boyer et al. (2013) and Kersalé et al. (2015); and from satellite altimetry in Herbert et al. (2011) and Le Henaff et al. (2011). Finally, the most intense circulation patterns are today explained by intermittent coastal densitydriven jets disturbed by tidal dynamics over the continental shelf, a slope current with seasonal and interannual reversals meandering to generate eddies and an open ocean region with a weak average circulation but several eddies propagating. From this statement, the next questions to be addressed to fulfil the scheme explaining the evolution of this coastal system concerns the mesoscale and submesoscale dynamics.

The underlying mechanisms of the mesoscale and submesoscale activity in the ocean have been widely described and discussed during the past years (e.g. McWilliams, 1985; Capet et al., 2008a, b, c; Klein et al., 2008; Ferrari, 2011; Scherbina et al., 2013; Sasaki et al., 2014; Callies et al., 2015; 

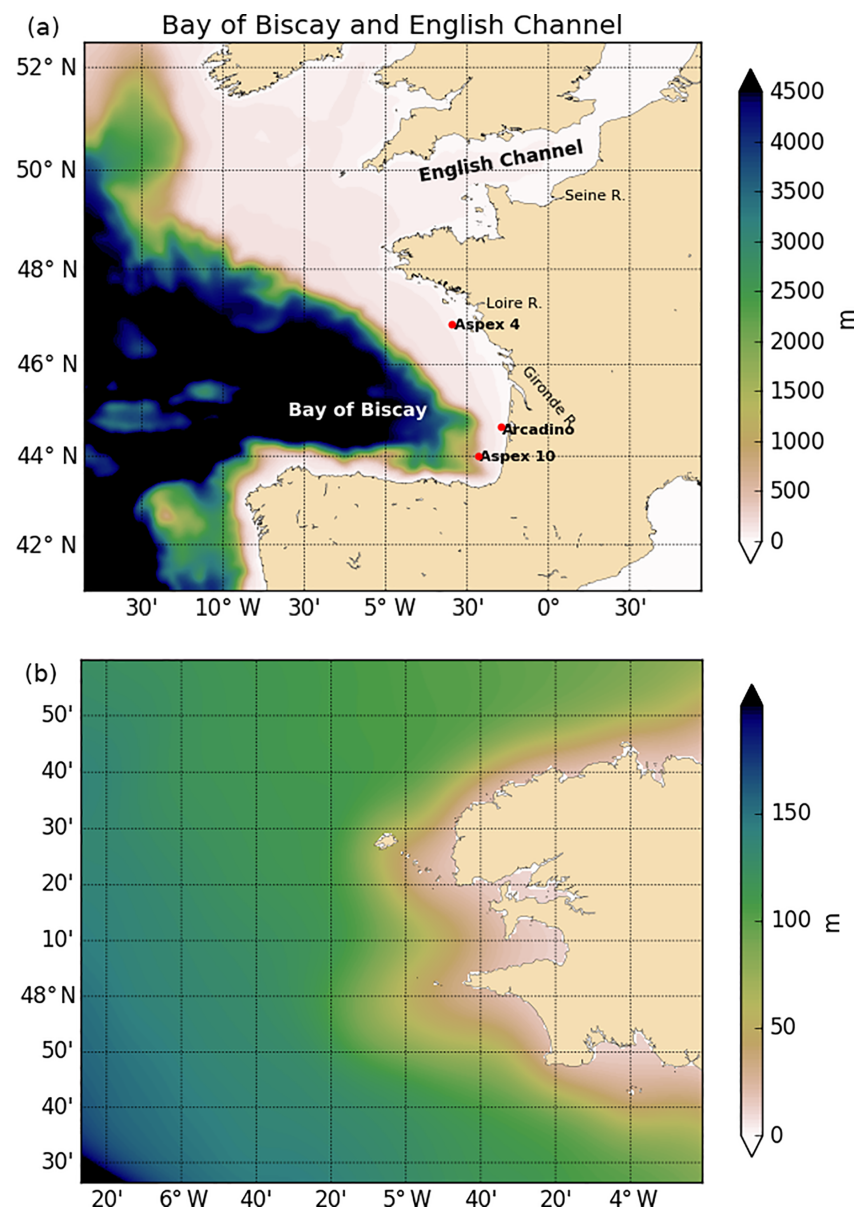

Figure 1. Bathymetry of the modelled region (a). Red points correspond to the mooring sites used for model validation. A zoomed-in area around $48^{\circ} \mathrm{N}$ is represented in panel (b).

Molemaker et al., 2015). This dynamics is particularly active (in terms of eddy kinetic energy) in western boundary currents.

In the present study, we aim at contributing to the description and the understanding of small-scale features in eastern boundary regions where the average level of kinetic energy remains low (Caballero et al., 2008; Dussurget et al., 2011) and of the mesoscale and submesoscale activity impact on long-term fluctuations related to evolution in atmospheric conditions.

The considered definition for the studied scales, depending on the depth of the water column and the stratification, has to be recalled as we progress in a coastal environment. In this framework, the mesoscale is defined by scales around the internal Rossby radius of deformation $(\sim 20-50 \mathrm{~km}$ in the midlatitudes; Chelton et al., 1998) where the flow is adjusted under the effect of the rotation. Over the continental shelf, this internal Rossby radius of deformation decreases to values around 3-8 km (M. Valdivieso Da Costa et al., personal communication, 2006), for example, in the Bay of Biscay. The submesoscale, as introduced by McWilliams (1985), refers to scales lower than the internal Rossby radius of deformation where the influence of the Earth's rotation tends to decrease in order to reach a non-rotating regime of three-dimensional turbulence (Kolmogorov, 1941). Submesoscale is then ranging from $\mathrm{O}(100) \mathrm{m}$ to $\mathrm{O}(10) \mathrm{km}$ over the continental shelf and in the open ocean (Capet et al., 2008b; Thomas et al., 2008). In the present work, we refer to (sub)mesoscale (i.e. mesoscale and submesoscale features) for processes with a length scale lower than $40 \mathrm{~km}$.

In the Bay of Biscay abyssal plain, coherent mesoscale structures have been identified like the long-lived anticyclonic Slope Water Oceanic eDDIES (SWODDIES) described by Pingree and Le Cann (1992a, b) generated by slope current instabilities or quasi-stationary eddies in the south-eastern Bay of Biscay (Caballero et al., 2013, 2016). Following satellite altimetry-based studies in the region $(\mathrm{Ca}-$ ballero et al., 2008; Dussurget et al., 2011), observations of mesoscale variability have been described with higher eddy kinetic energy from December to May. However, the spatiotemporal resolution and coverage from altimetry does not allow exploring underlying processes and interannual variability at submesoscale.

In this context, after controlling the efficiency and accuracy of a coastal model with a $1 \mathrm{~km}$ spatial resolution to reproduce the observed processes in the Bay of Biscay, the (sub)mesoscale variability at annual and interannual scales is explored as a first step to define the role of related vertical motions at small scales on long-term evolution and associated biogeochemical production.

\section{Numerical framework}

\subsection{Model description}

Numerical simulations are based on the MARS3D model ${ }^{1}$. MARS3D (Duhaut et al., 2008; Lazure and Dumas, 2008) is a primitive equation model with a free surface to represent the gravity waves in the coastal area. In this finitedifference code, the primitive equations are discretized on an Arakawa C-grid centred at tracer points (Mesinger and Arakawa, 1976). The sigma coordinates are used on the vertical dimension to resolve simultaneously the shallow and deep waters. A specificity of MARS3D model is that the barotropic mode and baroclinic mode are using the same time step and the barotropic mode is resolved by an alternating direction implicit method (Lazure and Dumas, 2008). Detailed equations are given in Appendix A.

The new numerical MARS code can run without explicit viscosity (Duhaut et al., 2008). The $k-\epsilon$ turbulent closure scheme is used to model vertical mixing (Rodi, 1993).

\footnotetext{
${ }^{1}$ http://wwz.ifremer.fr/mars3d
} 


\subsection{Numerical experiments}

The MARS3D model has already been used to investigate the Bay of Biscay and its extension to the western English Channel and focused on the validation of hydrology on the French continental shelf with a $4 \mathrm{~km}$ horizontal resolution and 30 vertical levels (Lazure et al., 2009). In this new configuration (Theetten et al., 2017), the model domain extends from the Bay of Biscay to the English Channel from 41 to $52.5^{\circ} \mathrm{N}$ and $14.3^{\circ} \mathrm{W}$ to $4.5^{\circ} \mathrm{E}$, with a $1 \mathrm{~km}$ spatial horizontal resolution with a time step of $\Delta t=60 \mathrm{~s}$. This configuration (called BACH1000_100lev) has $1449 \times 1282$ grid points and uses 100 vertical sigma levels. The vertical discretization is a generalized vertical, terrain-following coordinate system (with $h_{\mathrm{c}}=20 \mathrm{~m} ; \theta=6$ and $b=0 ; h_{\mathrm{c}}$ is the shallower depth above which we wish to have more resolution, $\theta$ and $b$ are surface and bottom control parameters; Appendix A). The bathymetry is a composite of several IFREMER digital terrain models (DTMs) with $100 \mathrm{~m}$ resolution along the coast covering the French part of continental shelf completed by a $1 \mathrm{~km}$ resolution DTM covering the bay of Biscay and finally completed by a 1 nautical mile resolution from the North West Shelf Operational Oceanographic System (http: //noos.bsh.de). Both digital terrain models and mean sea level are interpolated on the grid and merged (Fig. 1). Some hand editing has been performed in few key areas specially to correct spurious interpolation near the coastline. The maximum depth in the model is $5310 \mathrm{~m}$. The interpolated topographies are smoothed by selectively applying a local filter to reduce the $r$ factor to below $0.25(r=\Delta h / 2 h$, where $h$ is the depth of the water column; Haidvogel and Beckmann, 1999). River runoffs are provided from 95 chronological records (daily measurements and climatology for the past years when no observations are available) located on the Spanish, French, Dutch, British and Irish coasts.

Initial conditions for temperature, salinity, sea surface height, baroclinic and barotropic velocities (calculated from baroclinic components) are derived from a DRAKKAR global configuration named ORCA12_L46-MJM88 (Molines et al., 2014). At the open ocean boundaries, the same variables as initial conditions are used with adaptive boundary conditions in a sponge layer on the north, south and west boundaries (Marchesiello et al., 2001). The sponge layer width is $20 \mathrm{~km}$ and the maximum horizontal viscosity/diffusivity values are $100 \mathrm{~m}^{2} \mathrm{~s}^{-1}$ and 0 outside the open boundary layers. The tide with 14 harmonic constituents is imposed along the boundaries using the FES2004 ocean tide atlas (Lyard et al., 2006).

The atmospheric forcing, which drives the simulation presented here, is provided by ERA-Interim, produced by the European Centre for Medium-Range Weather Forecasts (ECMWF; Berrisford et al., 2011). Using the $2 \mathrm{~m}$ air temperature, atmospherical pressure, relative humidity, rain and cloud cover from ERA-Interim data, indirect calculation of the different components of the air-sea heat exchange are computed by several bulk formulae (from Lazure et al., 2009).

The simulation starts from 1 January 2001 and covers a 10-year period until 31 December 2010. A spin-up of 2 years is taken into account to set up an established seasonal cycle in the circulation even in the open ocean constrained by a large-scale solution forced in open boundary conditions. The analysed period is then run from 2003 to 2010. The BACH1000_100lev configuration is implemented on the Tier-1 supercomputer machine OCCIGEN provided by GENCI and hosted at CINES $^{2}$. The supercomputer OCCIGEN with a performance peak of 2.1 Pflops encompasses 2106 dual-socket nodes on an Intel Xeon Haswell cadenced at $2.6 \mathrm{GHz}$. A total of 12 cores are present on each socket. This numerical experiment was part of the "Big Challenges program" conducted during the VRS period from December 2014 to January 2015. Using a domain decomposition technique, the computational domain is split into 558 subdomains leading to the same number of MPI tasks with 12 OpenMP threads each. This hybrid MPI/OpenMP application runs on 6696 cores and produces daily averaged outputs using the input/output server $\mathrm{XIOS}^{3}$ specially implemented in MARS3D for this configuration.

\section{Bay of Biscay features from a spatial high-resolution simulation}

Before exploring (sub)mesoscale features in the Bay of Biscay, the ability of the numerical experiment to reproduce known processes in the region needs to be evaluated. Following a general view of the modelled fields, a few key diagnostics on the hydrology and the circulation are presented.

\subsection{Sea surface temperature and salinity}

The numerical experiment is validated using remotely sensed sea surface temperature (SST). Based on SEVIRI SST remotely sensed data (METEOSAT SST provided by OSI-SAF belonging to EUMETSAT with $\sim 2 \mathrm{~km}$ spatial resolution), modelled fields are evaluated. In Fig. 2a, the mean bias between observed and modelled SST over 2010 is computed:

$$
\begin{aligned}
\left\langle\mathrm{SST}_{\text {bias }}\right\rangle_{\text {long, lat }, t} & =\left(\frac{1}{\left(N_{i} N_{j} N_{t}\right)} \sum_{i=1, j=1, t=1}^{N_{i}, N_{j}, N_{t}} \mathrm{SST}_{i, j, t}^{\text {model }}\right) \\
& -\left(\frac{1}{\left(N_{i} N_{j} N_{t}\right)} \sum_{i=1, j=1, t=1}^{N_{i}, N_{j}, N_{t}} \mathrm{SST}_{i, j, t}^{\text {observations }}\right),
\end{aligned}
$$

where $N_{i} N_{j} N_{t}$ is the number of grid points in space and time.

\footnotetext{
${ }^{2}$ http://www.cines.fr, Centre Informatique National de l'Enseignement Supérieur (CINES)

${ }^{3} \mathrm{http}: / /$ forge.ipsl.jussieu.fr/ioserver
} 
(a) SST bias (model - observations) over the domain
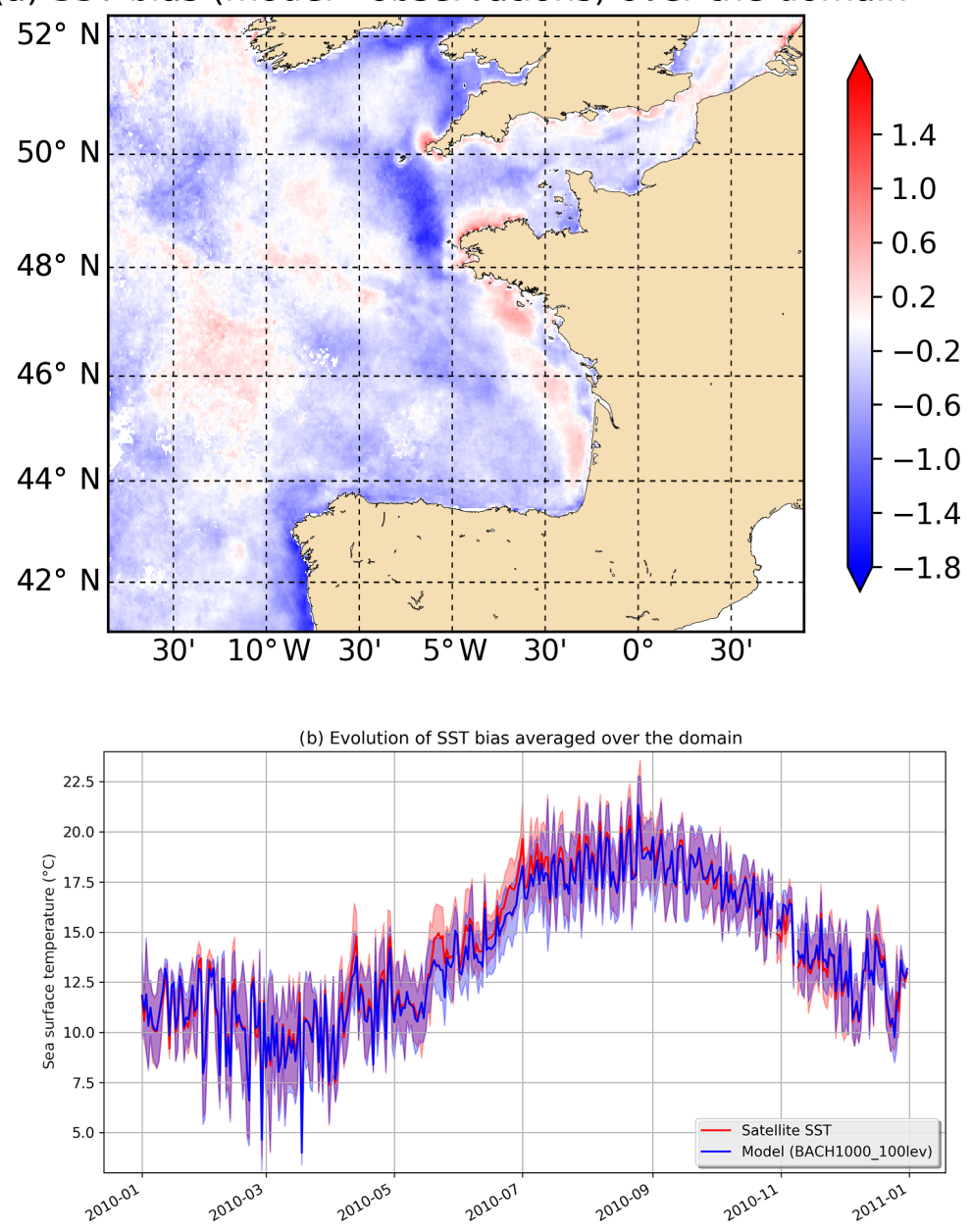

Figure 2. Comparison between observed (SEVIRI satellite SST) and modelled (BACH1000_100lev simulation) sea surface temperature (SST). (a) Mean bias between model and observations for the year 2010. (b) Temporal evolution of the spatial mean SST bias during 2010. The shading around the curves represents the spatial standard deviation (i.e. the standard deviation over the domain computed for each time step).

At the end of the experiment, this bias shows an averaged underestimation of the temperature by the model $\left(-0.24 \pm 0.28^{\circ} \mathrm{C}\right.$ over the domain). These biases do not exceed $1.75^{\circ} \mathrm{C}$. Such large values are obtained in two regions. First, in the Ushant front region (around $47.5-49^{\circ} \mathrm{N}$ and 5$6^{\circ} \mathrm{W}$; Le Boyer et al., 2009), the model underestimates the SST. This bias can be explained by the variability of the Ushant front, developed during stratified seasons, which remains complex to reproduce (Renaudie et al., 2011; Pasquet et al., 2012). The second main bias exceeding $1.5^{\circ} \mathrm{C}$ is located along the western Spanish coast. The shape of the bias is typical of upwelling extent in this region. In this case, the coarse atmospheric forcing resolution can be emphasized as the major error source. Figure $2 b$ shows the temporal varia- tion of the spatial averaged bias:

$$
\langle\mathrm{SST}\rangle_{\text {long, lat }}(t)=\frac{1}{\left(N_{i} N_{j}\right)} \sum_{i=1, j=1}^{N_{i}, N_{j}} \operatorname{SST}_{i, j, t},
$$

where $N_{i} N_{j}$ is the number of grid points in space. The shading around the curves represents the spatial standard deviation:

$$
\sqrt{\frac{1}{\frac{1}{\left(N_{i}-1\right)\left(N_{j}-1\right)} \sum_{i=1, j=1}^{N_{i}, N_{j}}(t)=}\left(\operatorname{SST}_{i, j}-<\mathrm{SST}>_{\text {lon,lat }}(t)\right)^{2}} .
$$

At this regional scale and on average over the full domain, we do not observe significant permanent bias in the simulation. Both simulations and observations have the same average and temporal variations in surface temperature with a 

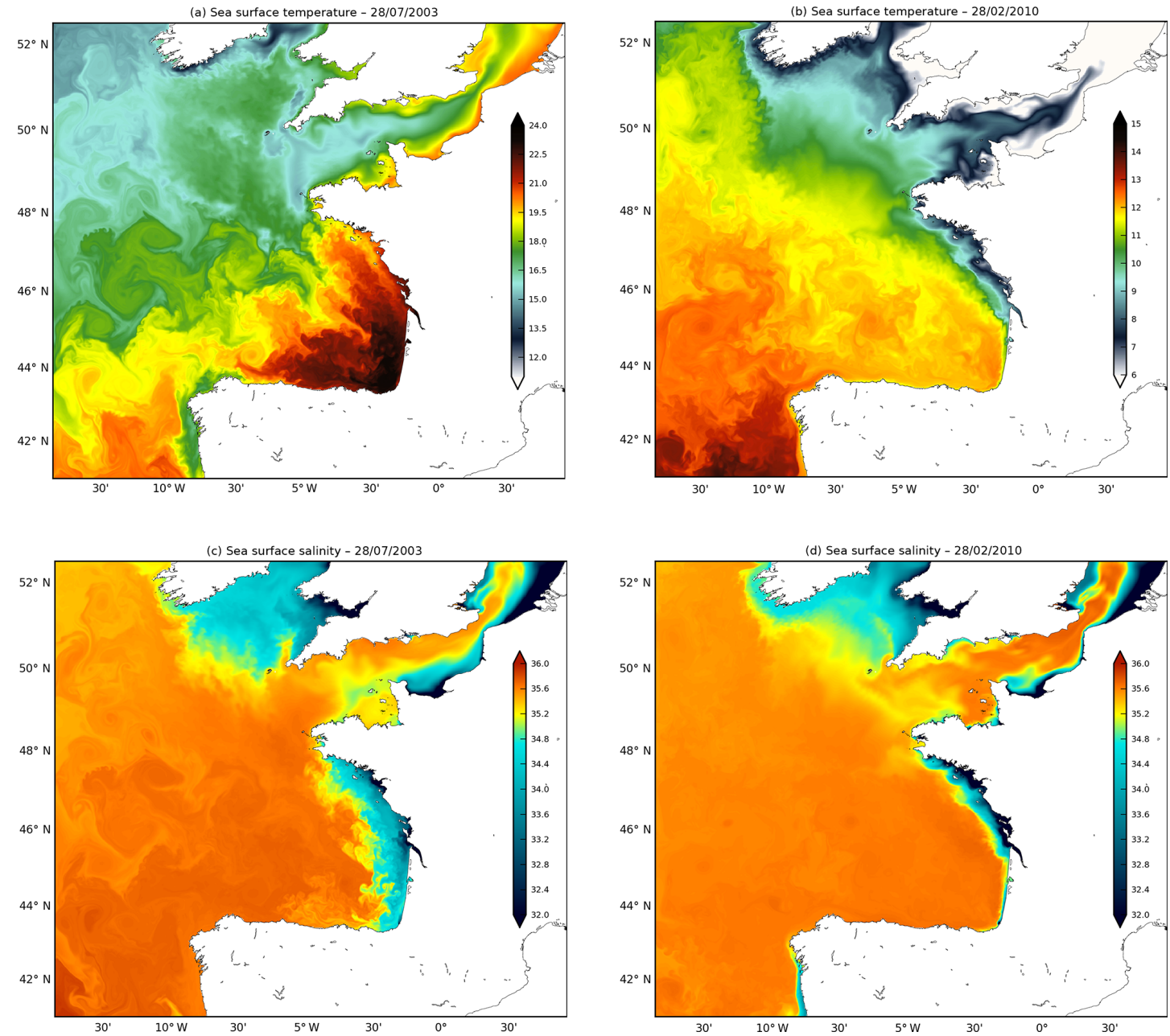

Figure 3. Example of modelled (BACH1000_100lev configuration) sea surface temperature (a, b) and salinity (c, d) in summer (a, c 28 July 2003) and winter (b, d - 27 February 2010).
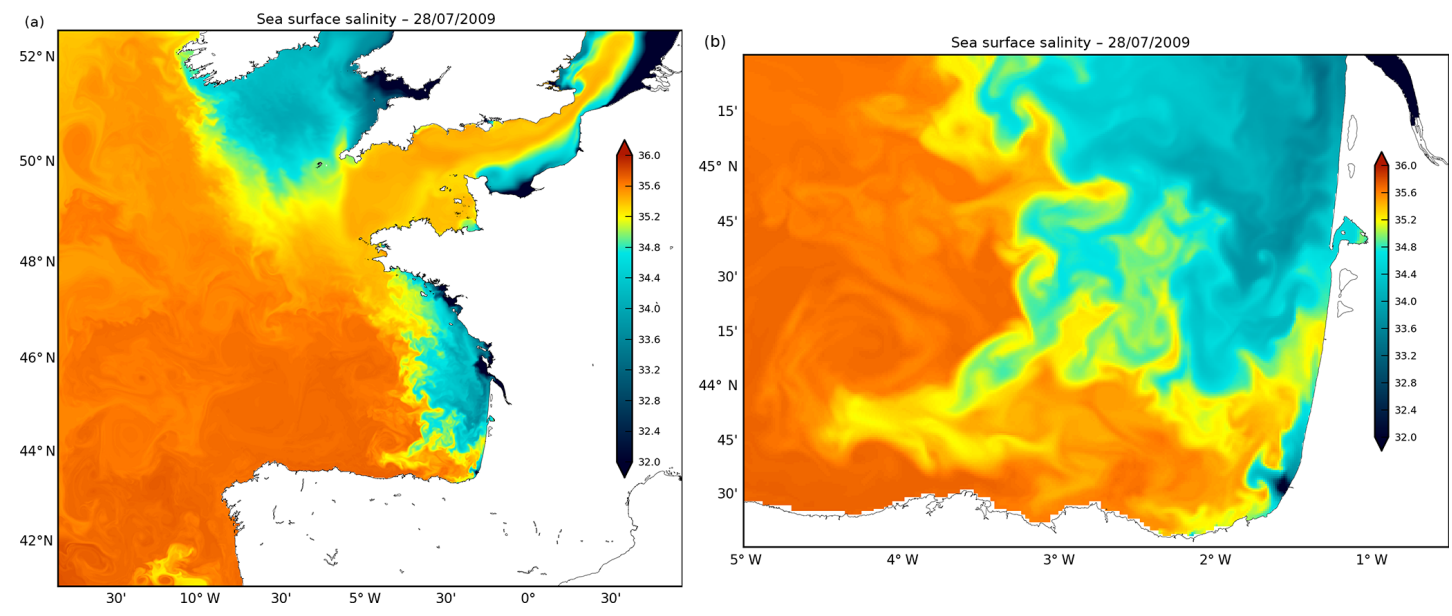

Figure 4. Sea surface salinity (28 July 2009) during an event of freshwater export in the open ocean as described by Reverdin et al. (2013). Panel (a) represents the full model domain and (b) is focused on the south-eastern part of the Bay of Biscay to highlight the freshwater export around $44^{\circ} \mathrm{N}$ and $3.5^{\circ} \mathrm{W}$. 

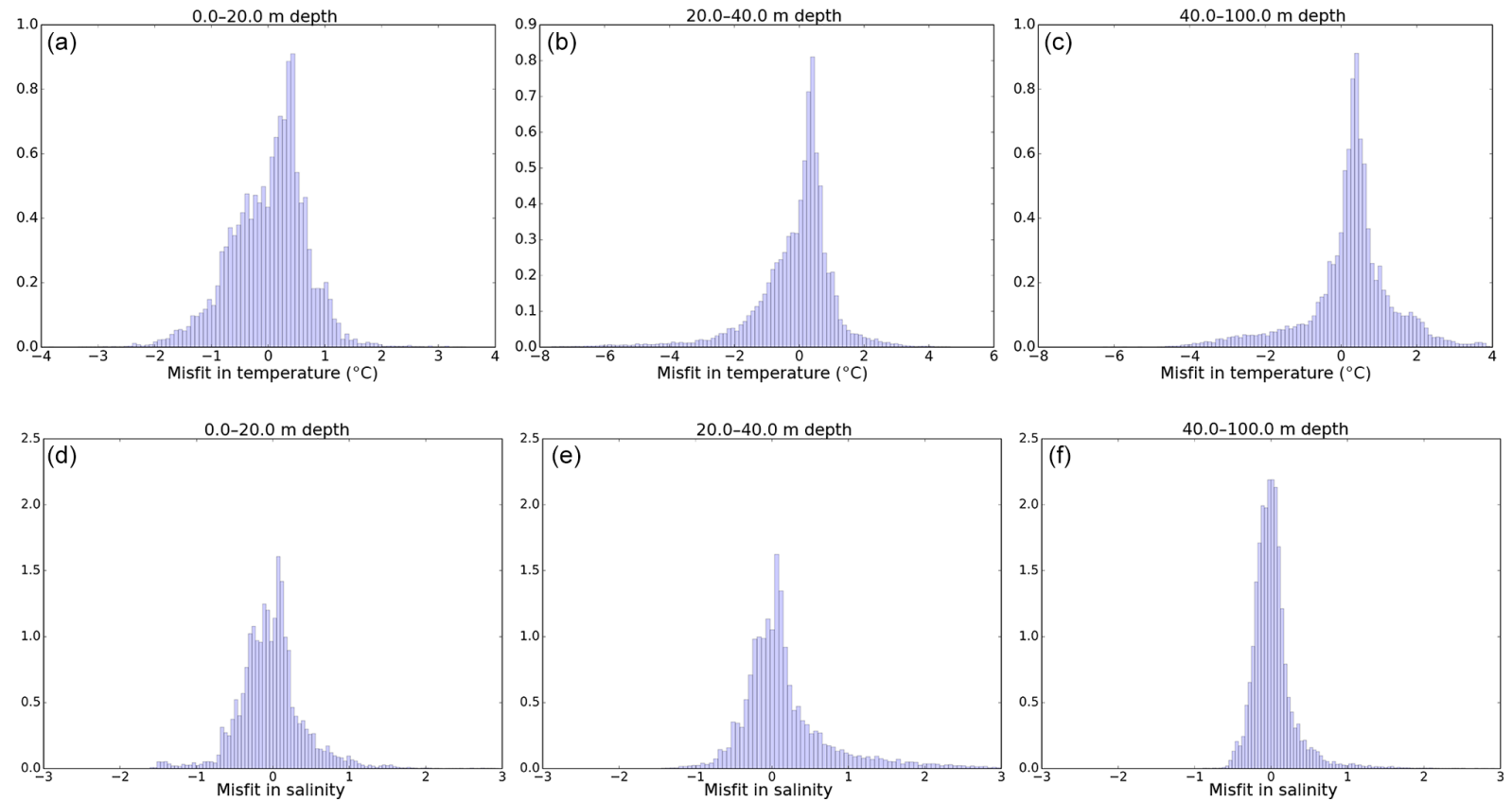

Figure 5. Normalized distribution of the misfit (modelled-observed) in temperature (a, b, c) and salinity (d, e, f) from RECOPESCA and Argo in situ profiles (only for profiles deeper than $100 \mathrm{~m}$ ) for three vertical layers: 0-20 m depth (a, d), 20-40 m depth (b, e) and 40-100 m depth (c, f). The integral of the histogram sums up to 1 .

developed seasonal cycle with maximum temperature in August and September and the coldest waters at the end of winter in March. The largest differences can be noticed during the onset of the seasonal stratification in May-June.

After this first overview on SST, two contrasted dates (summer and winter) are displayed in Fig. 3 for SST and sea surface salinity (SSS). In summer (Fig. 3a), the model reproduces the warm pool in the south-eastern part of the Bay of Biscay with temperature exceeding $21^{\circ} \mathrm{C}$ (Lazure et al., 2009). In front of Brittany $\left(48.2^{\circ} \mathrm{N}, 5.6^{\circ} \mathrm{W}\right)$, the position of the Ushant tidal front (Le Boyer et al., 2009; Renaudie et al., 2011; Pasquet et al., 2012) with cold waters in the vicinity of the coast and warmer water outside the front is reproduced by model simulations. In winter, colder (Fig. 3b) and fresher (Fig. 3d) waters above the inner shelf related to river plume extent do not exceed $9^{\circ} \mathrm{C}$ and salinity of 34.8 .

Furthermore, in Fig. 3, turbulent activity (eddies, filaments) can be noticed during summer and winter in the deeper region but also over the continental shelf.

As a more focused illustration, freshwater exports in the open ocean, as described in Reverdin et al. (2013), appear in the present experiment (Fig. 4). The elongated freshwater filaments extending to the south-west in the southern part of the Bay of Biscay $\left(44^{\circ} \mathrm{N}, 3.5^{\circ} \mathrm{W}\right)$ represent an observed signal of cross-slope exchanges. Reproducing these exports is a significant step forward in our simulations, thanks to the higher spatial resolution ( $1 \mathrm{~km}$ vs. $4 \mathrm{~km}$ in previous experiments). Indeed, the spatial resolution appeared as a key issue to bet- ter resolve these exchanges between the continental shelf and the open ocean.

\subsection{Vertical hydrological structure}

The hydrological content of the simulation is evaluated through comparisons with available observations in 2010 from the CORA-IBI (COriolis ocean database for ReAnalysis - Ireland-Biscay-Iberia, Szekely et al., 2017) database. Considered vertical profiles can be divided into two sources: Argo (Argo, 2000; Riser et al., 2016) profiles in the open ocean and RECOPESCA (Leblond et al., 2010; Charria et al., 2014; Lamouroux et al., 2016) profiles on the continental shelf.

Figure 5 shows the difference between observed and modelled profiles for the year 2010 in temperature and salinity in the top layers. In temperature, the model reproduces the vertical structure with a small average misfit of 0.015 and a $0.45^{\circ} \mathrm{C}$ root mean square error (RMSE) between 0 and $20 \mathrm{~m}$ depth (Fig. 5a), $-0.11^{\circ} \mathrm{C}\left(1.23^{\circ} \mathrm{C}\right.$ for RMSE) between 20 and $40 \mathrm{~m}$ depth (Fig. 5b) and $0.25^{\circ} \mathrm{C}\left(1.17^{\circ} \mathrm{C}\right.$ RMSE) between 40 and $100 \mathrm{~m}$ depth (Fig. 5c). This misfit can be observed in the distribution in Fig. 5. Following the uncertainties around the thermocline (i.e. a few metres of differences in the thermocline depth will induce large difference between model and observations) the misfit distribution is larger below $20 \mathrm{~m}$ depth. Similar behaviour is observed in salinity with the larger spread for the layer $20-40 \mathrm{~m}$ depth. In salinity, the average misfit is smaller at the surface $(-0.024$ for the 

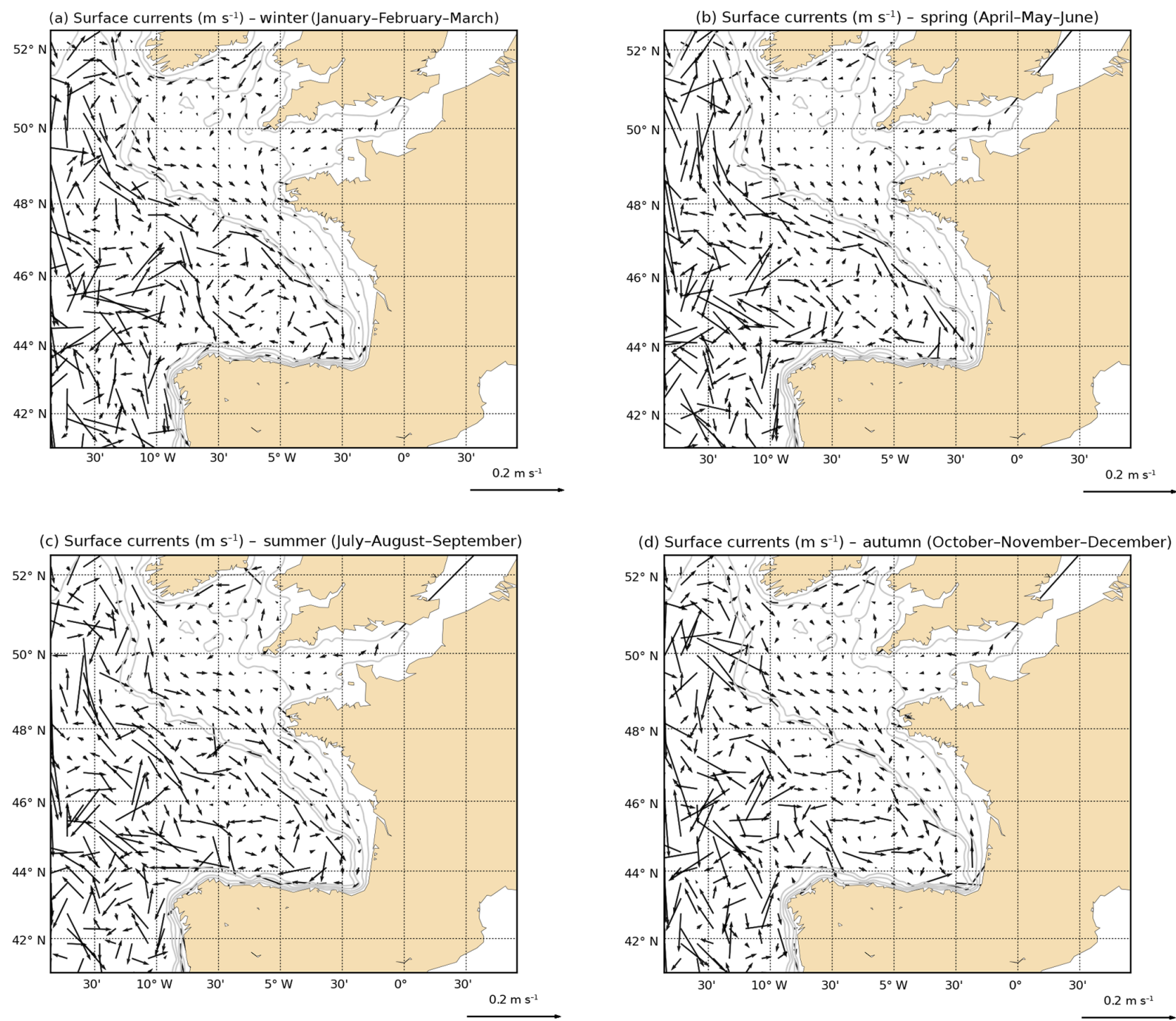

Figure 6. Average modelled seasonal circulation (a: winter, b: spring, c: summer, d: autumn) for surface layers $(0-50 \mathrm{~m}$ depth) over the period 2001-2010 (for clarity purposes, fields have undersampled and 1 over 50 grid points are plotted). Gray lines represent 500, 200, 100 and $50 \mathrm{~m}$ isobaths.

layer 0-20 m depth, RMSE $=0.27$; Fig. $5 \mathrm{~d})$ and above $100 \mathrm{~m}$ depth $(0.025$ for the layer $40-100 \mathrm{~m}$ depth, RMSE $=0.28$; Fig. 5e and $\mathrm{f}$ ) than between 20 and $40 \mathrm{~m}$ depth where the average difference is larger $(0.176, \mathrm{RMSE}=0.59)$. Considering the RMSE, we confirm that the maximum of error is located in mid-depth layers $(20-40 \mathrm{~m})$ and can be locally important. Part of the error can be attributed to the colocation approach assuming that we will reproduce the same features at the same time and place in the simulations, but choices for the configuration (e.g. smoothed bathymetry, coarse atmospheric forcings) can contribute to increasing the observed error between model and local in situ observations. However, following the distributions, with biases of different signs following the depth, no systematic bias exists in the numerical experiment.

\subsection{Bay of Biscay general circulation}

Concerning the general circulation in the region, three levels of comparisons are detailed. As a synoptic view, the seasonal circulation in the surface layer is computed to be compared with existing climatologies (e.g. Charria et al., 2013). Then, to highlight circulation patterns occurring at short timescales as poleward jets over the continental shelf (e.g. Batifoulier et al., 2012; Kersalé et al., 2015) and the vertical structure of the currents, modelled fields are compared with ADCP observations during the ASPEX campaign (Le Boyer et al., 2013; Kersalé et al., 2015) and the front of the Arcachon Bay during the ARCADINO campaign (Batifoulier et al., 2012).

At seasonal scale, Fig. 6 shows the circulation integrated over the first $50 \mathrm{~m}$ depth for the whole simulation. This average circulation over 10 years can be compared with the cli- 

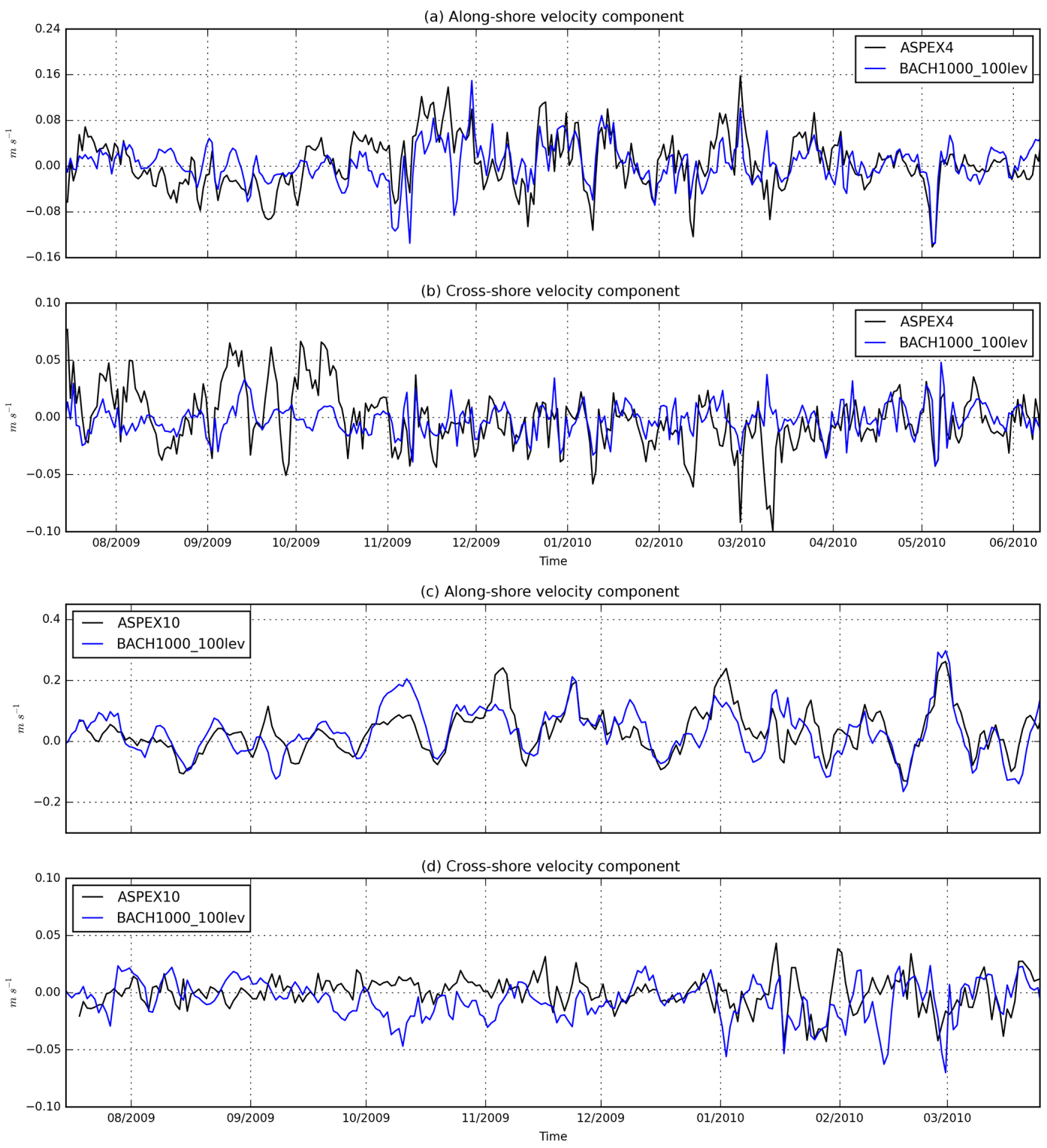

Figure 7. Comparison of the 1-day mean and depth averaged along-shore and cross-shore velocity components between ADCP measurements (black) and BACH1000_100lev currents (blue) at the location of ASPEX4 (Fig. 7a and b) above the continental shelf and ASPEX10 (Fig. 7c and d) above the continental slope. The orientation of the along-shore and cross-shore components is relative to the bathymetry.

matology (processed from observation from 1992 to 2009) derived from drifters in Charria et al. (2013). In winter (Fig. 6a), the contrasted velocities with weak current over the continental shelf and more intense structures in the open ocean clearly appear. The poleward slope current with values lower than $10 \mathrm{~cm} \mathrm{~s}^{-1}$ is reproduced. In spring (Fig. 6b), the reversal of circulation with an equatorward slope current is simulated. This circulation remains sustained in summer (Fig. 6c) with a reinforcement of equatorward currents over the continental shelf. Following wind regime evolution and the transition period in September-October (SOMA seasonal response; Pingree et al., 1999), autumn circulation (Fig. 6d) highlights, on average, the poleward slope current close to the $500 \mathrm{~m}$ isobath. These average circulation features are then in agreement with the drifter-derived seasonal climatology (Charria et al., 2013).

Another source for validating the modelled circulation comes from ADCP deployments in the region. During the ASPEX project, 10 current-meter moorings were deployed from July 2009 to August 2011. The mooring location was distributed over the continental shelf and the upper section of the shelf break. Mooring features and observations from the project are described and analysed in Le Boyer et al. (2013) and Kersalé et al. (2015).

Two ASPEX ADCP moorings have been selected to compare evolution of current velocities with modelled fields: no. 


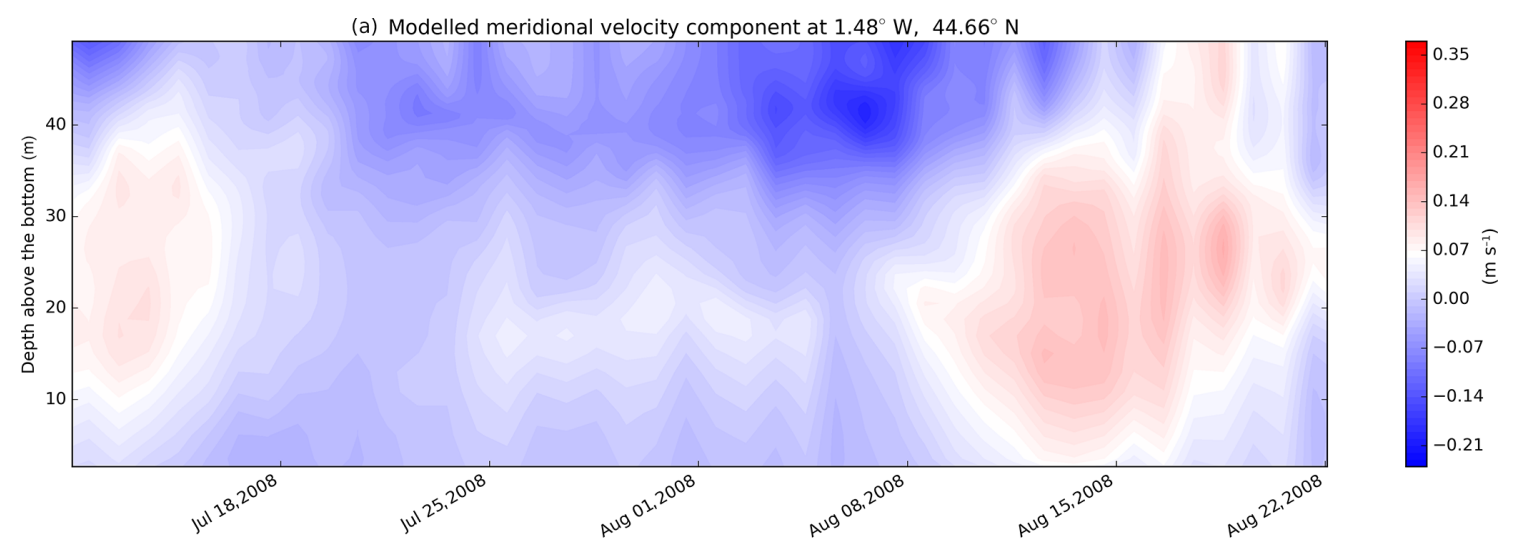

(b) Observed meridional velocity component at $1.45^{\circ} \mathrm{W}, 44.65^{\circ} \mathrm{N}$

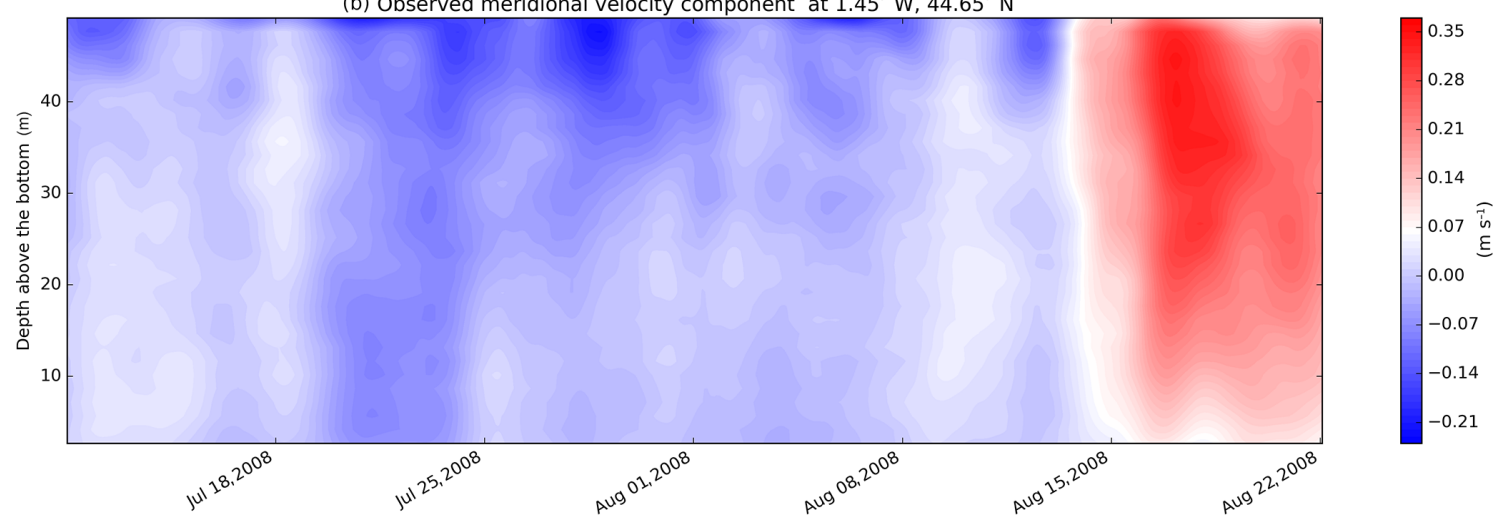

Figure 8. Evolution of meridional velocity component in $\mathrm{m} \mathrm{s}^{-1}$ of the BACH1000_100lev model during July-August 2008 (a) at the ARCADINO ADCP location. ADCP observations for the same periods are represented (b).

4 on the continental shelf and no. 10 on the continental slope (see positions in Fig. 1). We can notice that the length of the considered time series for comparison is both limited by the duration of the numerical experiment (2001-2010) and the technical issues in data sampling (lack of measurements for the end of the ASPEX10 time series). Two-dimensional linear spatial interpolation on model output velocity components at each sigma level is made on the geographical position/location of the mooring. Then, the zonal and meridional components of modelled velocities are projected on alongshore and cross-shore component at each sigma level. In the aim to compare the depth-averaged velocity on both model outputs and in situ data, vertical integration of the two velocity components is made on almost the whole water column ${ }^{4}$. Vertical integration of the model outputs is also made on the water column between the minimum and maximum depths defined previously.

In Fig. 7, the modelled and observed currents are represented. A general agreement following the current directions and amplitudes is observed with correlations between 0.6

\footnotetext{
${ }^{4}$ The first record is located near the bottom. Records located in the surface layer thickness (corresponding to $20 \%$ of the mooring depth) have been removed due to noisy measurements.
}

and 0.69 for along-shore components. For the cross-shore component, representing the less intense currents, in ASPEX4 (Fig. 4b), the direction of the current is well reproduced but the amplitude remains generally smaller in simulations $\left(\mathrm{RMSE}=0.024 \mathrm{~m} \mathrm{~s}^{-1}\right.$ ). At ASPEX10 (Fig. 4d), the cross-shore weak circulation is not reproduced, with a correlation between model and observation equal to 0.09 , due to the mesoscale circulation in this area (e.g. Solabarrieta et al., 2014; Caballero et al., 2016). The agreement between observations and numerical simulation is improved for dominant along-shore currents. Indeed, amplitudes are very similar in both ASPEX sites (except during autumn 2009; Fig. 4a and c). The direction and direction changes are also very well reproduced (the correlation for ASPEX4 is equal to 0.6 and for ASPEX10 to 0.69), even at high frequency, which was not expected following the coarse atmospheric forcings used for the simulation.

Other comparisons have been performed with an ADCP mooring during the ARCADINO experiment. This mooring, located on the Aquitaine shelf (south of $45^{\circ} \mathrm{N}$; Fig. 1), has been used to highlight poleward coastal jets up to $32 \mathrm{~cm} \mathrm{~s}^{-1}$ (Batifoulier et al., 2012). Similar events are modelled in our numerical experiments with smaller amplitudes (Fig. 8). In 2008, a poleward along-shore current appears around $15 \mathrm{Au}$ - 

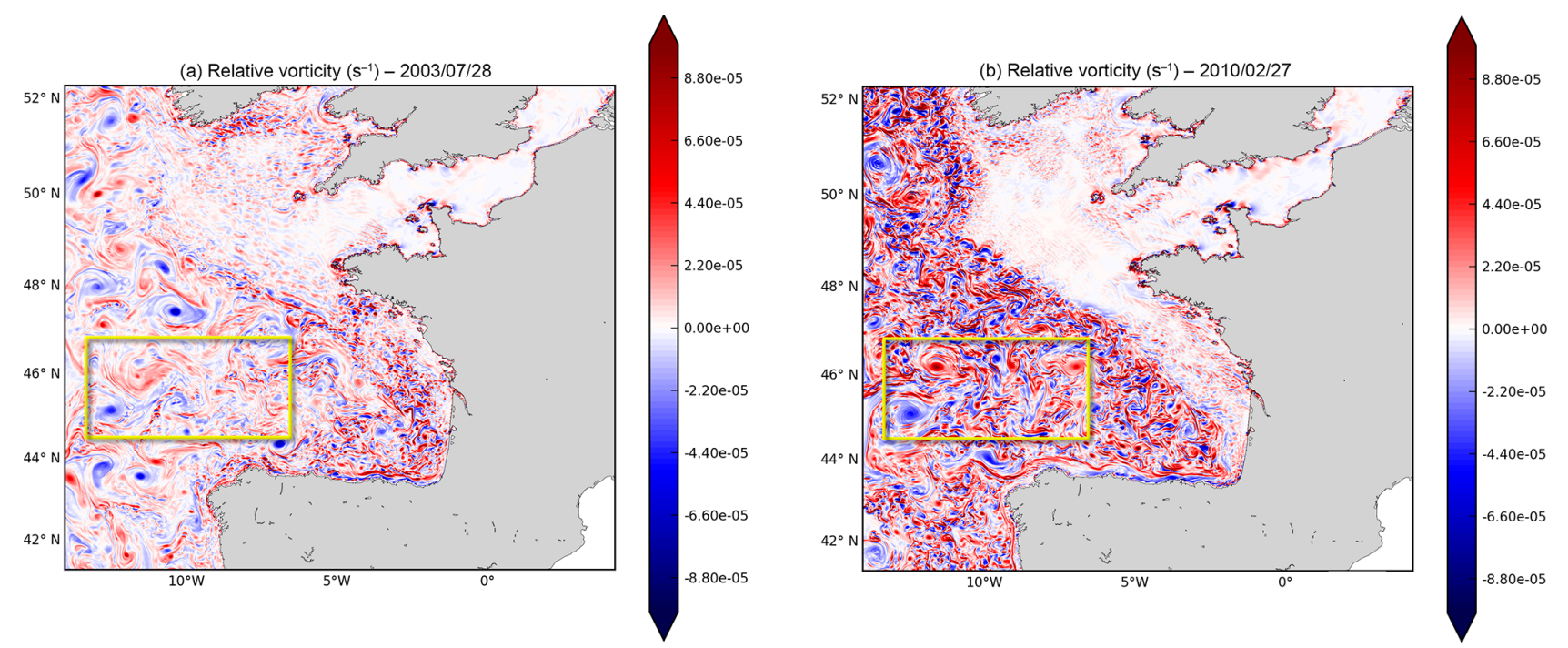

Figure 9. Surface modelled relative vorticity for 28 July 2003 (a) and 27 February 2010 (b). The yellow rectangle limits the targeted region for diagnostics.

gust 2008 (Fig. 8) in observations. From in situ ADCP measurements (Batifoulier et al., 2012), there is also a velocity maximum between 16 and 20 August 2008. In the modelled fields, the jet is reproduced but velocities are weaker and the event starts earlier in the simulation. The jet is also deeper in the model (20-40 $\mathrm{m}$ depth with maximum velocities $\sim 16 \mathrm{~cm} \mathrm{~s}^{-1}$ ) than in observations with a maximum above $30 \mathrm{~m}$ depth. When model forcings are explored, we explain this event with similar conditions to those observed in Batifoulier et al. (2012). Indeed, westerly winds are blowing from the 6 to 8 August (with intensities 8 to $12 \mathrm{~m} \mathrm{~s}^{-1}$ ) along the Spanish coast to set up the circulation resulting in the poleward jet following the explained process in Batifoulier et al. (2012).

These illustrations of the modelled fields and comparisons with available observations show the ability and the limits of our numerical experiment to reproduce the coastal ocean dynamics at high resolution in the Bay of Biscay. Based on these fields, the interannual variability at (sub)mesoscales can be explored.

\section{Interannual variability of (sub)mesoscale instabilities in surface layers}

The present study aims to characterize the interannual variability of the (sub)mesoscale dynamics and discuss the possible processes explaining this variability. Before considering these interannual scales, the seasonal features are described for a given year.

\subsection{Seasonal scale}

To explore the (sub)mesoscale activity, the vertical component of the relative vorticity (referred as relative vorticity) has been first analysed. From these dynamical fields, we can infer the intensity of rotating structures and their spatial distribution.

In Fig. 9, the surface relative vorticity from analysed simulations at different contrasted time steps is represented. From these maps, different patterns can be noticed. First, the contrast between the deep open ocean and the shallow continental shelf is clearly visible for the different periods. In summer 2003 (Fig. 9a), over the continental shelf, the internal waves are observed in the northern part of the domain spreading from the shelf break (around 47.5-48 $\mathrm{N}, 7-5^{\circ} \mathrm{W}$ ). In the southern part of the continental shelf (south of $48^{\circ} \mathrm{N}$ ), small structures related to local drivers (e.g. edge of region of freshwater influence, wind bursts; O. Yelekci et al., personal communication, 2016) are developed. These structures can be seen through large relative vorticity values over the outer part of the continental shelf between the $100 \mathrm{~m}$ isobath (Fig. 6) and the shelf break (Fig. 1). In contrast, in winter (Fig. 9b), small-scale features are more concentrated in the inner shelf (the first half of the continental shelf closer to the coast with water shallower than $100 \mathrm{~m}$ depth) under the influence of large winter river inputs (e.g. mainly from the Loire and Gironde rivers).

When we consider the open ocean over the abyssal plain, contrasted situations with structures with smaller relative vorticity in summer (Fig. 9a) and more intense small vortices in winter (Fig. 9b) are clearly observed. Smaller features (eddies and filaments with spatial scales lower than $40 \mathrm{~km}$ ) are fully developed in winter. In summer, typical spatial scales 


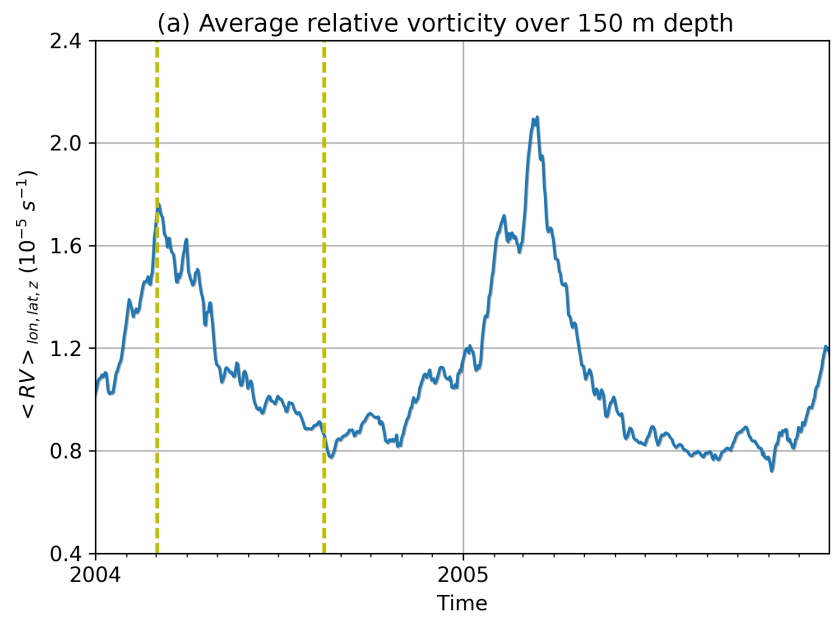

(a)

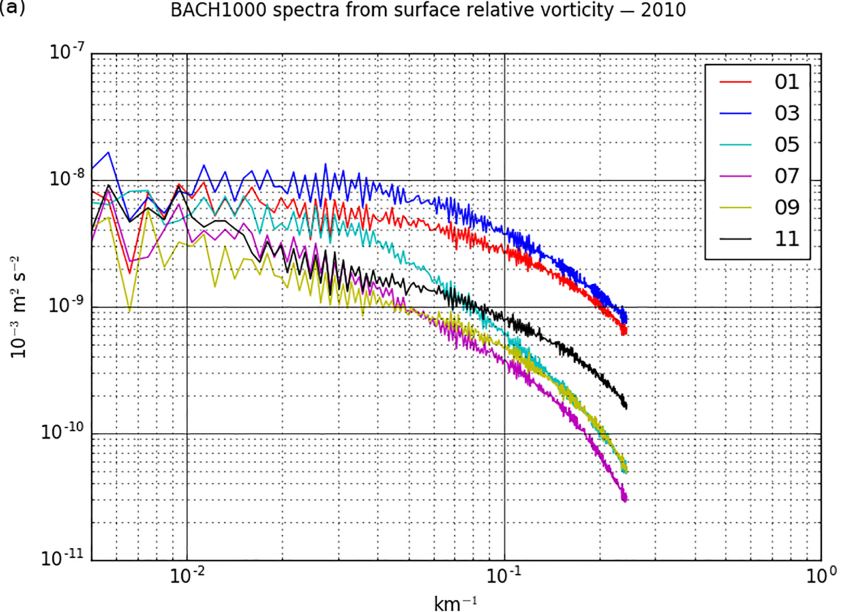

(b) Relative vorticity $\left(10^{-4} \mathrm{~s}^{-1}\right)-2004 / 03 / 02$

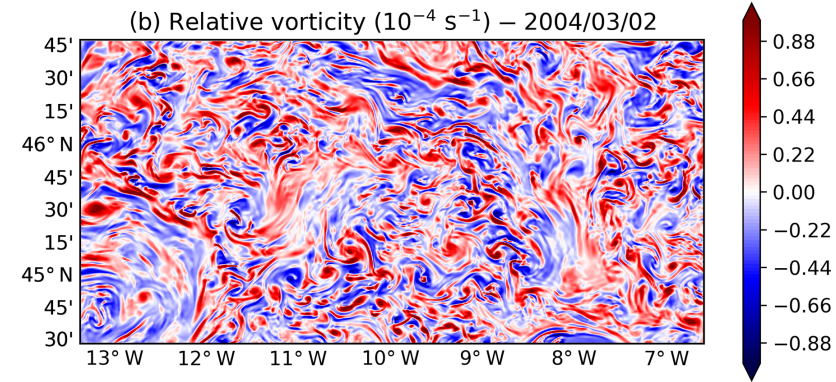

(c) Relative vorticity $\left(10^{-4} \mathrm{~s}^{-1}\right)-2004 / 08 / 15$

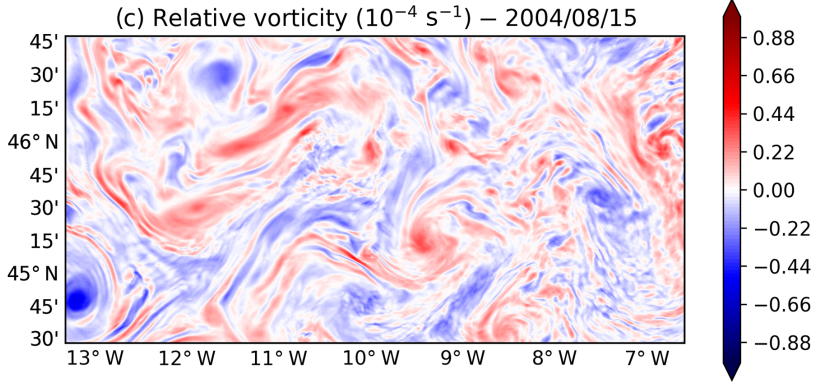

Figure 10. Relative vorticity averaged over $150 \mathrm{~m}$ depth and spatially averaged for the years 2004 and 2005 (a). Map of the surface relative vorticity for 2 March 2004 (b) and 15 August 2004 (c).

are larger than in winter. More large-scale vortices are simulated during this season. The spatial spectral analysis over the domain (Fig. 11) confirms the largest small-scale $(<50 \mathrm{~km}$ wavelength) variance peaks in winter (maximum in March) and the minimum variance at small scale in summer (July).

Based on Fig. 10, representing the years 2004 and 2005, a picture of the annual evolution of the relative vorticity intensity can be drawn considering a spatial average of the absolute relative vorticity over the region highlighted in Fig. 9 (yellow rectangle). Based on the spatial average integrated over $150 \mathrm{~m}$ depth $^{5}$ (Fig. 10a), a maximum is observed dur-

\footnotetext{
${ }^{5}$ This depth $(150 \mathrm{~m})$ has been defined to include most of the mixed layer depth in winter. As it is used for the whole time se-
}

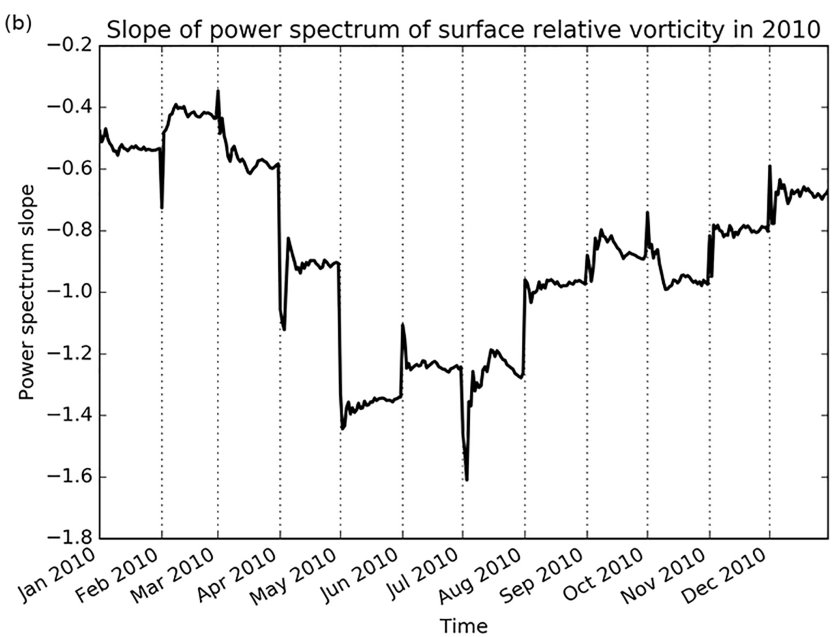

Figure 11. Power spectrum (computed for each latitude and averaged over longitudes and time during the considered month) from surface relative vorticity for the year 2010 (a). Numbers in the legend correspond to the months in the year 2010. Time series of the regressed spectral slope from the power spectrum of surface relative vorticity in 2010 (b). Spectral slopes have been computed considering wavelengths from 7 to $132 \mathrm{~km}$.

ing the end of winter (February-March) followed by a period (June-September) corresponding to a minimum of averaged relative vorticity. The horizontal patterns (Fig. 10b and c) associated with these average time series confirm the larger range of relative vorticity values related to smallscale structures. In summer (Fig. 10c), intensity of eddies is decreased with larger-scale features (e.g. structures with a length scale larger than $50 \mathrm{~km}$ ). This decrease in the intensity of the modelled field can also be described through the surface relative vorticity spectra computed from each month (Fig. 11). These spectra have been computed every day over the limited domain (yellow rectangle in Fig. 9) using a 2-D fast Fourier transform and then averaged over the considered

ries (including stratified seasons), the maximum mixed layer depth (around 200 to $250 \mathrm{~m}$ on average) has not been taken as a reference. 

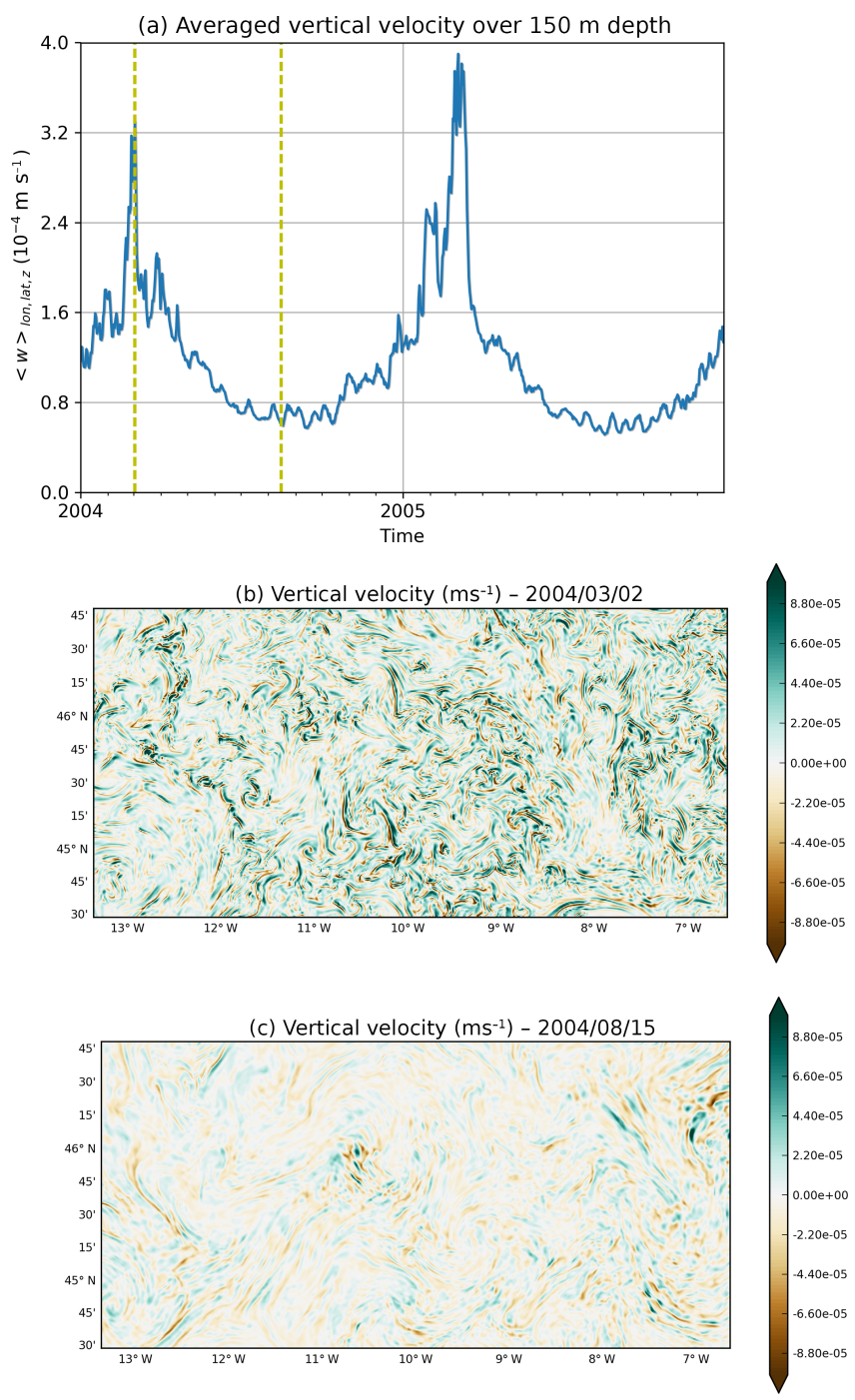

Figure 12. Vertical velocity averaged over $150 \mathrm{~m}$ depth and spatially averaged for the years 2004 and 2005 (a). Map of the vertical velocity at $4 \mathrm{~m}$ depth for 2 March 2004 (b) and 15 August 2004 (c).

month. These spectra clearly show the seasonal variation of the variance with a maximum in March and a minimum in July. An increase in the variance of small scales (lower than $50 \mathrm{~km}$ ) is also observed through a change in the curve slope observed in November, January and March compared with May, July and September.

Following the relative vorticity fields (i.e. related to vortices, fronts, filaments), vertical motions can also be explored. The role of structures at (sub)mesoscale on these vertical motions can be highlighted by the exploration of vertical velocities (significant vertical velocity patterns are mainly at submesoscales and mesoscales). Indeed, in Fig. 12a, a similar seasonal cycle with relative vorticity is observed with a maximum of integrated vertical velocity at the end of winter (February-March) and a minimum in summer (JuneSeptember). Based on the spatial patterns of the vertical ve-

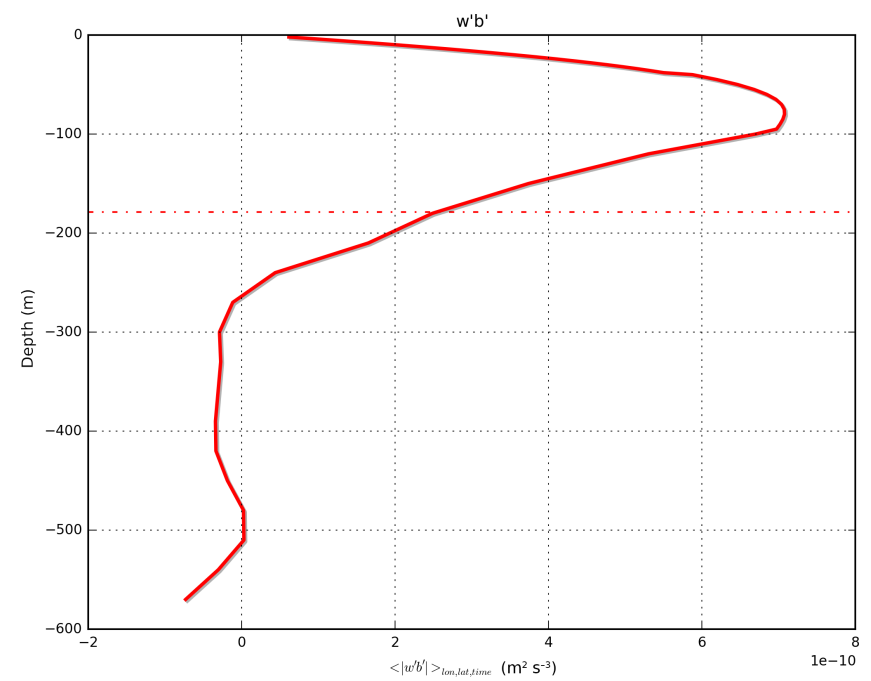

Figure 13. Vertical profile of $w^{\prime} b^{\prime}$ averaged over the studied subdomain (described in Fig. 9) during the winter season (JanuaryFebruary-March) in 2005. The dashed line represents the mixed layer depth averaged for the same period over the considered region.

locity fields (Fig. 12b and c), intense and small structures are observed at the end of winter (Fig. 12b) that have developed with small typical length scales. In summer, positive and negative vertical velocity patterns are more elongated due to aggregated patterns (Fig. 12c) and less activity at small scale.

A vertical signature of the fluctuations in the (sub)mesoscale regimes can be inferred from the (sub)mesoscale component of the vertical buoyancy flux $\left(w^{\prime} b^{\prime}\right.$, where $w$ is the vertical velocity and $b$ the buoyancy) computed following

$\left\{\begin{array}{l}w=\bar{w}+w^{\prime} \\ b=\bar{b}+b^{\prime}\end{array}\right.$

with

$b=-g \frac{\left(\rho-\rho_{0}\right)}{\rho_{0}}$,

where $\bar{w}$ and $\bar{b}$ are filtered field using a 2-D convolution with a Hanning window of $40 \mathrm{~km}$ length scale. $w^{\prime} b^{\prime}$ is then representing spatial scales smaller than $40 \mathrm{~km}$.

The diagnostic $\left(w^{\prime} b^{\prime}\right)$ translates the conversion rate of available potential energy to eddy kinetic energy (e.g. Boccaletti et al., 2007; Fox-Kemper et al., 2008a, b), which tends to be maximal in the mixed layer in the case of vertical velocities related to mixed layer instabilities (Boccaletti et al., 2007; Stone, 1966, 1970). In Fig. 13, the vertical profile of $w^{\prime} b^{\prime}$ averaged over the studied subdomain during the winter season (January to March) shows a maximum (reaching, on average, $3.1 \times 10^{-10} \mathrm{~m}^{2} \mathrm{~s}^{-3}$ ) in surface layers corresponding to the mixed layer. 
(a) Averaged verrtical velocity over $150 \mathrm{~m}$ depth

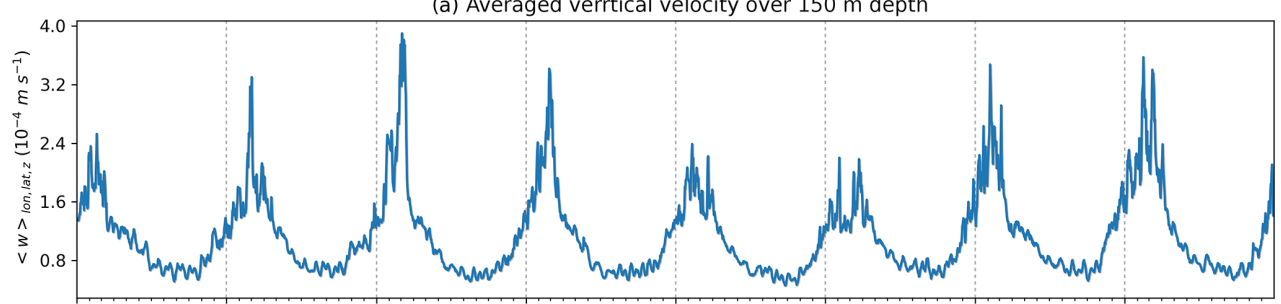

(b) Averaged relative velocity over $150 \mathrm{~m}$ depth

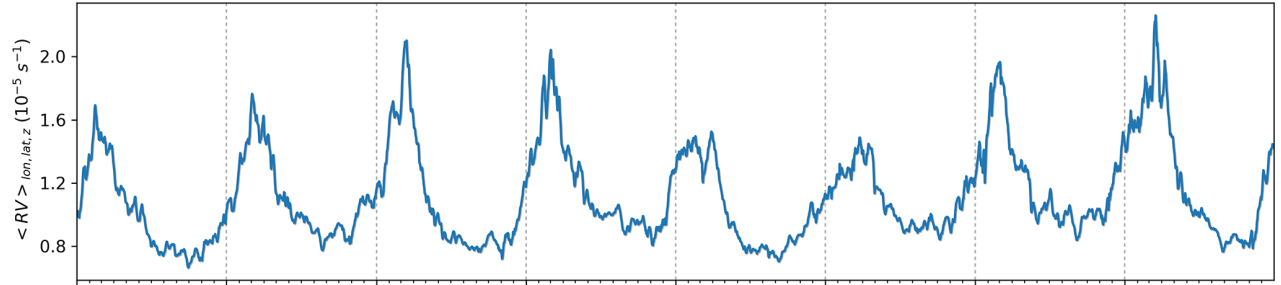

(c) Averaged temperature over $150 \mathrm{~m}$ depth

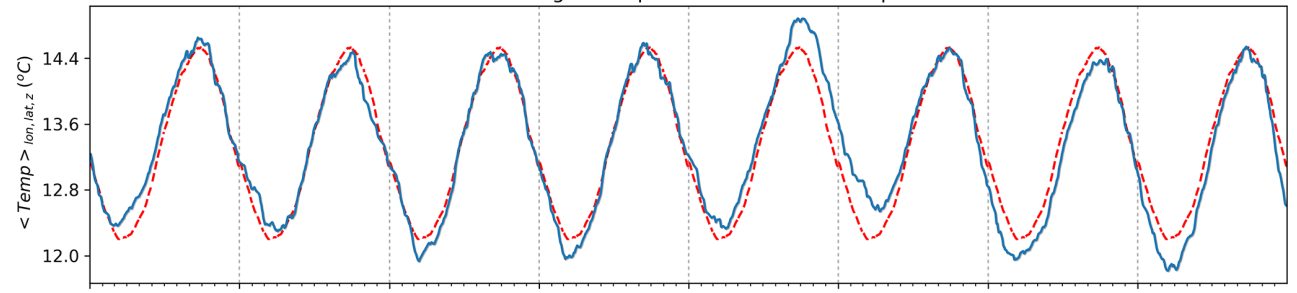

(d) Averaged salinity over $150 \mathrm{~m}$ depth

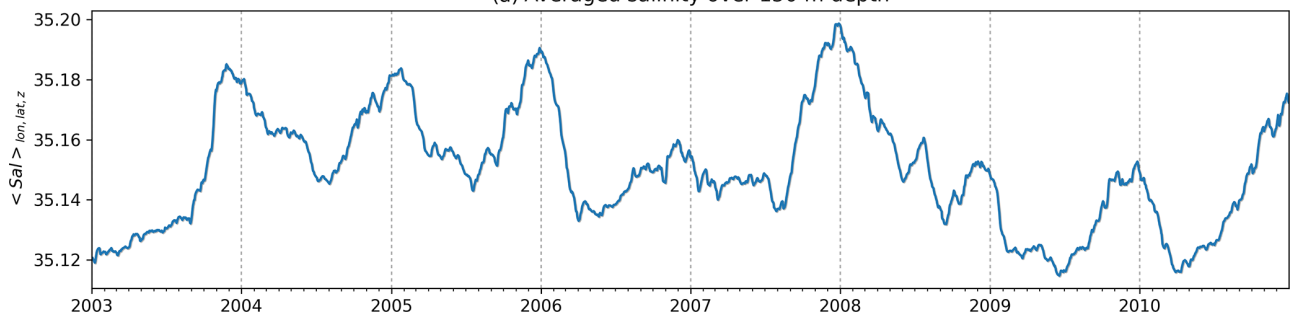

Figure 14. Interannual variability (from 2003 to 2010) of spatially averaged vertical velocity (a), relative vorticity (b), temperature (the red dashed line is the average annual cycle during the modelled period) (c) and salinity (d) integrated over $150 \mathrm{~m}$ depth. The considered domain is given in Fig. 9.

Following the seasonal description, 10 years of highresolution simulations allow consideration of the interannual variations.

\subsection{Interannual scale}

The different regimes modelled in 2004 and 2005 are also observed during the whole simulated period (2003-2010; the first 2 years are not taken into account considering a spinup period). Indeed, in Fig. 14a (vertical velocity) and 14b (relative vorticity), a maximum appears generally at the end of winter at the same time for both quantities. The intensity of the maximum displays interannual fluctuations with larger values in 2004 (only for vertical velocity), 2005, 2006, 2009 and 2010. In contrast, 2003, 2007 and 2008 are characterized by a weaker (sub)mesoscale activity. The maxima are in phase with the coldest period in temperature, and the most extreme values in vertical velocity and relative vorticity correspond to the most extreme cold values in temperature compared with the annual cycle (Fig. 14c) before the spring warming and the beginning of seasonal stratification. The most extreme vertical velocities are simulated during winter 2005 with a peak in the beginning of March 2005. In contrast, positive anomalies in temperature are modelled from September 2007 to May 2008. For winter before (beginning of 2007) and during this period (winter 2008), minimum vertical velocities and relative vorticity are observed over the 8year period. In 2009, the winter situation comes back to cold sea temperature anomalies related with more intense vertical velocities and relative vorticity.

As we consider an area not under direct influence of major river runoffs (far from the slope dynamic barrier), the salinity (Fig. 14d) does not exhibit a regular seasonal cycle. Indeed, the main sources of freshwater in the Bay of Biscay come from river discharges. These discharges follow a seasonal cycle with a maximum flow at the end of winter 


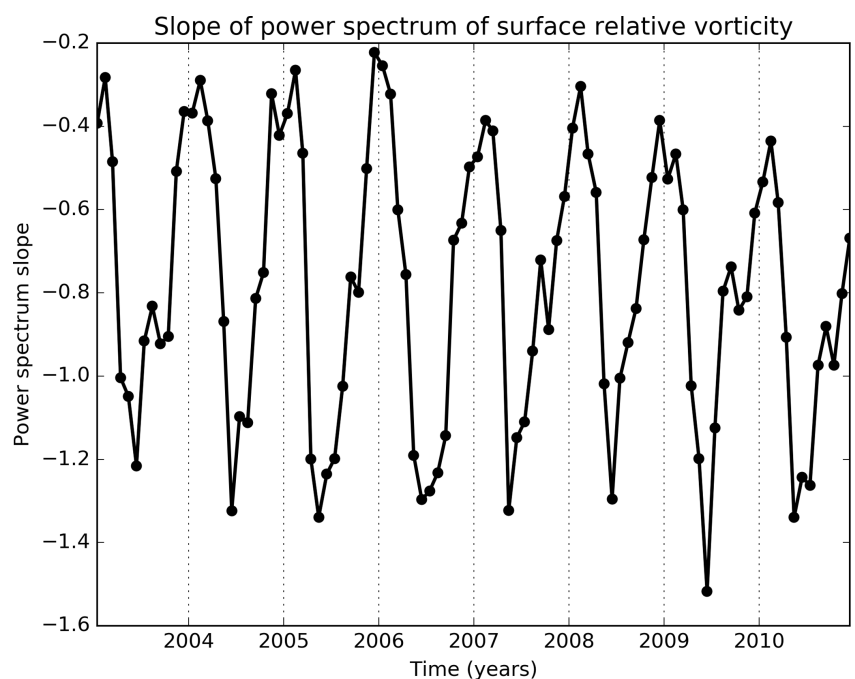

Figure 15. Time series of the regressed spectral slope from the power spectrum of surface relative vorticity from 2003 to 2010. Spectral slopes have been computed considering wavelengths from 7 to $132 \mathrm{~km}$.

not simulated over the analysed domain. Furthermore, the evaporation-precipitation budget (related to the more intense and frequent cyclonic weather systems in winter) does not induce large variations at seasonal scales in the region but fluctuates interannually depending the atmospheric conditions.

The role of the different spatial scales in this interannual variability is explored through the analysis of the slope of the power spectrum of surface relative vorticity. Figure 15 shows the shallowest slopes (larger than $k^{-0.4}$ ) occurring in autumn/winter (from November to March). In contrast, slopes values are steeper (between $k^{-1.2}$ and $k^{-1.4}$ ) in spring with a minimum in May or June. The interannual variability of this minimum (corresponding to steepest slopes) is limited and values are very similar following the year. Concerning the shallowest winter slopes, the value is decreasing with time but the limited number of simulated years does not allow conclusion to the significance of this trend. The monthly seasonal cycle is very stable every year. However, we can notice that in 2004 the shallowest slopes are reached earlier (in November) than during the other years (December, January or February). The interannual variability of the spectral slope gives then an overview of the evolution of the distribution of spatial scales.

\section{Discussion}

Model simulation, validated with available observations, exhibits a seasonal cycle related to small-scale features in the deep part of the Bay of Biscay. This region, despite low levels of eddy kinetic energy (e.g. Caballero et al., 2008; Charria et al., 2013), is the location of development of mixed layer instability dynamics similar to those observed in the western
Pacific Ocean (e.g. Sasaki et al., 2014), the western North Atlantic (e.g. Mensa et al., 2013; Callies et al., 2015) and the eastern North Atlantic (e.g. Thompson et al., 2016). Following the analogy, the features from mixed layer instabilities (Boccaletti et al., 2007) are confirmed by the maximum of activity simulated at the end of winter when vertical buoyancy fluxes at (sub)mesoscale are the most intense and with a maximum of conversion rate between available potential energy and eddy kinetic energy at (sub)mesoscale in the mixed layer depth 6 (Fig. 13). These instabilities drive a conversion in kinetic energy of the stored potential energy in winter and can lead to reinforcing the seasonal stratification.

Therefore, in a realistic modelling framework, these results corroborate the suitable spatial $(1 \mathrm{~km})$ and vertical resolutions $(100 \sigma$ levels) to solve the (sub)mesoscale realistic features resulting from mixed layer instabilities. Indeed, Soufflet et al. (2016), based on ROMS simulations in a baroclinic jet test case, showed the sensitivity of the vertical buoyancy flux to the spatial resolution $(20,10,5$ and $2 \mathrm{~km})$ with a maximum mixed layer buoyancy flux for the higherresolution model. In the present study, the reproducibility of the results balancing between the winter unstable field and summer smoothed mesoscale activity after 10 years of simulation further shows the interest of the $\mathrm{O}(1 \mathrm{~km})$ scale in regional modelling. Previous interannual experiments with $4 \mathrm{~km}$ spatial resolution (not shown) also confirm the improvements.

The system described in the Bay of Biscay then follows a scheme where end-of-winter mixed layer instabilities will feed the eddy kinetic energy in the region. However, interannual fluctuations are clearly visible (Fig. 14) and can have an effect on the intensity of instabilities. A first link has been established between the winter mixed layer depth and the submesoscale activity. Indeed, Fig. 16a, representing the averaged mixed layer depth in the studied region, is correlated with the evolution of the relative vorticity and associated vertical velocities (Fig. 14a and b). The maximum intensity of vertical velocities is related to the maximum depth of the mixed layer. This relationship can be explained by the amount of available potential energy stored following these deep mixed layers. Following the potential impact of such fluctuations (maximum average vertical velocities can be doubled following the considered year) on the mixing and then on systems under this pressure (e.g. biogeochemistry), identifying the source of such variability becomes a key point to forecasting seasonal small-scale dynamics. A first driver potentially explaining deeper mixed layer depth for some years is the mechanical energy input (e.g. Duhaut and Straub, 2006; Huang et al., 2006; Elipot and Gille, 2009) related with the wind stress and the surface ocean velocity (the surface ocean velocity effect is generally smaller than

\footnotetext{
${ }^{6}$ The criterion selected for the mixed layer depth is a threshold value of density from a near-surface value at $10 \mathrm{~m}$ depth equal to $0.03 \mathrm{~kg} \mathrm{~m}^{-3}$ following de Boyer Montégut et al. (2004).
} 

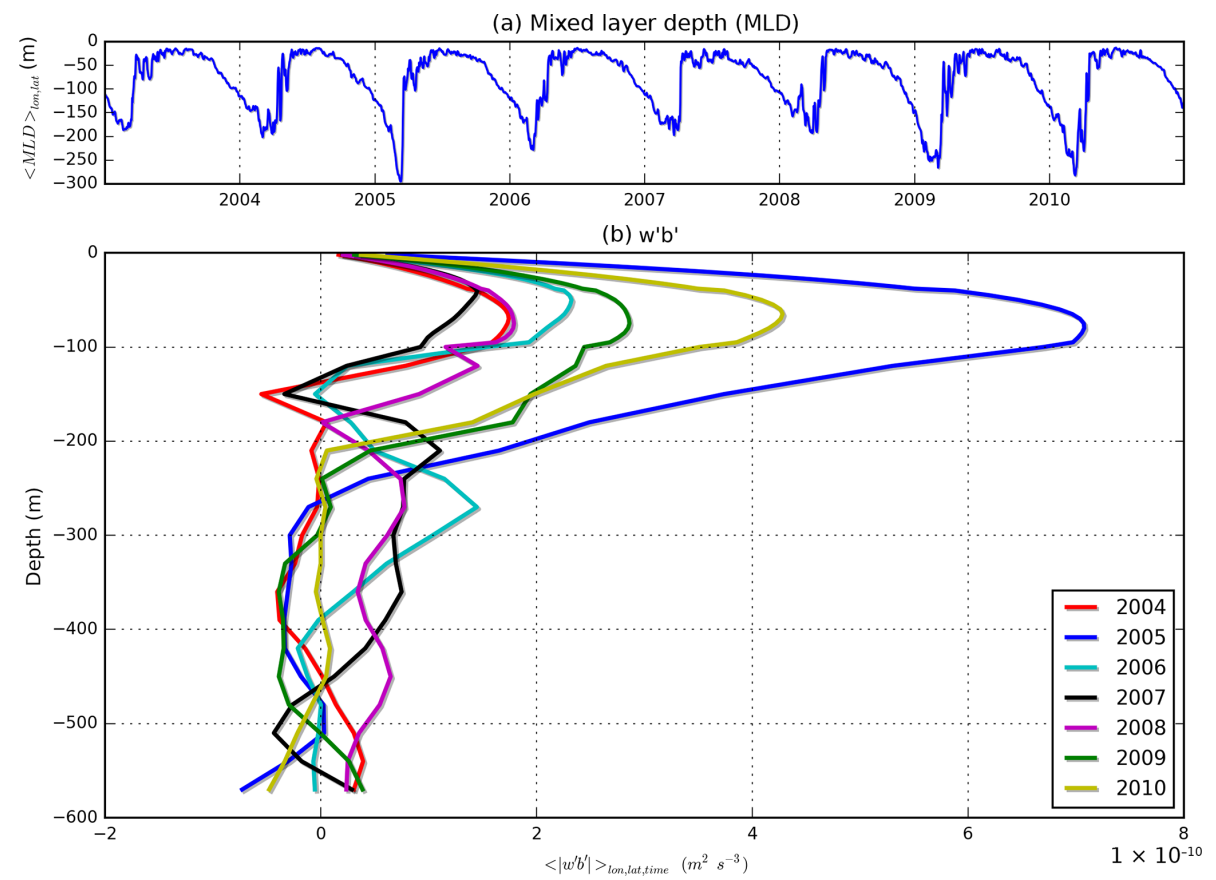

Figure 16. (a) Averaged mixed layer depth in the studied region (Fig. 9). (b) Vertical profiles of $w^{\prime} b^{\prime}$ averaged over the same domain during winter seasons (January-February-March).

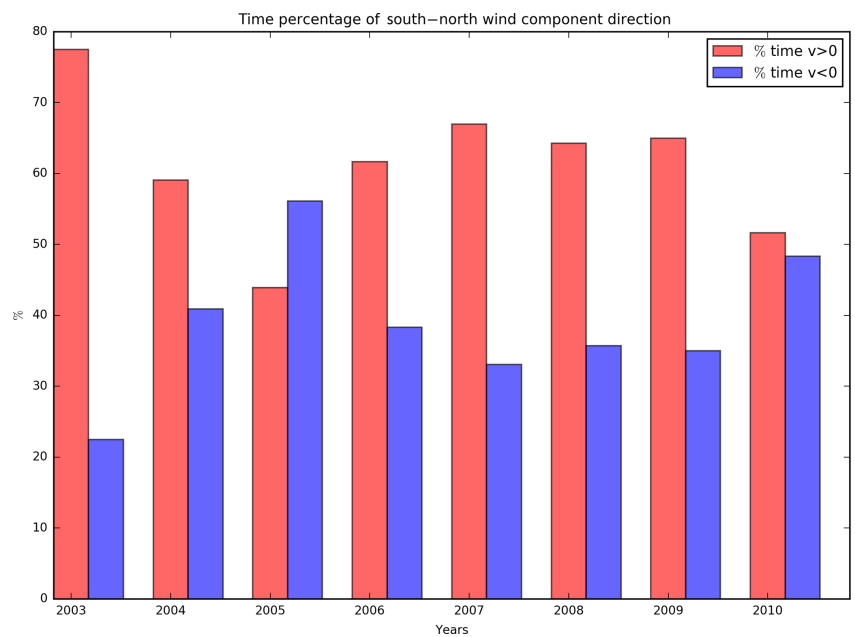

Figure 17. Statistics on the northerly and southerly winds during winters (January-February-March). Based on atmospheric forcings, the percentages of occurrence of northerly (in blue) and southerly (in red) winds are represented.

the wind stress impact). Variations of this large-scale source of energy have been explored in the Bay of Biscay and do not explain the interannual variations of the mixed layer depth in the region (not shown).

The alternative source of convective processes deepening the mixed layer depth in winter is the heat fluxes (mostly latent and sensible heat fluxes in winter in the region following Somavilla et al., 2011). During the simulated period, the extremely cold and dry winter in 2005 (Somavilla et al., 2009, 2011, 2016) explains the deepest average mixed layer depth over the domain. This winter was very specific with dominant northerly wind (Fig. 17) advecting cold air in the Bay of Biscay. This cold air mass influences the air-sea temperature gradient and then the associated heat fluxes. This extreme winter is associated with the largest vertical buoyancy flux at (sub)mesoscale (Fig. 16b). Following the same behaviour, the years 2009 and 2010 also reach deep mixed layer depth maxima (deeper than $250 \mathrm{~m}$; Fig. 16a) associated with an intense associated vertical buoyancy flux. Similarly, the year 2010 is associated with an important occurrence of northerly winds (Fig. 17). The modelled deep mixed layer for these years was observed by Hartman et al. (2014) from in situ Argo vertical profiles in the Bay of Biscay. These specific years (2009 and 2010) were also associated with cold winters.

On the contrary, 2007 and 2008 had shallower mixed layer depth maxima (Fig. 16a) associated with a reduced maximum of vertical buoyancy flux at (sub)mesoscale (Fig. 16b). These shallower mixed layers are related to warm winters causing warming of the surface ocean and a decrease in winter mixing. Indeed, during winter 2007, the surface air temperature was probably the highest recorded during the past 500 years (Luterbacher et al., 2007).

Winter 2006 is an intermediate state due to the remaining effect of sea surface temperature anomaly during winter 2005 (Dummousseaud et al., 2010). 
The analysis can be extended to the distribution of the dominant spatial scales. Based on power spectra and the evolution of the spectral slopes (Fig. 15), the analysis does not show interannual evolution in the distribution of spatial scales except at the end of 2004 where we can observe that the maximum slope is reached in November, earlier than during other analysed years. During the whole period, slopes remain located between $k^{-0.4}$ and $k^{-1.4}$. This range is in agreement with modelling studies based on similar resolutions. For example, in Brannigan et al. (2015), spectral slopes for surface velocities for simulation with similar resolution ( 1 and $2 \mathrm{~km}$ ) are located between $k^{-2}$ and $k^{-4}$. Taking into account the velocity derivative in the relative vorticity, slopes from the present study are equivalent to slopes between $k^{-2.4}$ and $k^{-3.4}$ in surface velocities.

Based on these distributions, the potential impact of large-scale interannual variability on the small-scale features is mainly observed for extreme conditions (e.g. autumn 2004/winter 2005) where the early decrease of the slope translates to an anticipated increase of the variance at small scales.

\section{Conclusions}

With the rise of numerical capabilities, coastal dynamics can be explored at regional scale over pluri-annual periods keeping a high spatial resolution needed to solve at the (sub)mesoscale. Based on a $1 \mathrm{~km}$ spatial resolution numerical experiment over 10 years, we explored the (sub)mesoscale dynamics in the Bay of Biscay and its interannual evolution.

Before exploring interannual variability for few-kilometre scales, the ability of the model to reproduce multi-scale processes (from intermittent events to average circulation) has been shown, including sustaining a coherent circulation after 10 years of simulation.

Based on these products, and despite low levels of eddy kinetic energy linked with an eastern boundary circulation system, the seasonal cycle in the turbulent regimes with a smaller scale at the end of winter and a maximum in relative vorticity and vertical velocities at the end of winter (in March) is shown. The source of these small-scale structures is associated with mixed layer instabilities.
Then, the investigations focused on interannual variability in the (sub)mesoscale are linking the evolution in the maximum of small-scale vertical velocities with the maximum mixed layer depth reached during the ongoing winter. Differences between intensities of (sub)mesoscale activity can then be related to the winter conditions explaining mixed layer dynamics. Cold winters are characterized by deeper mixed layer depth (2005, 2009 and 2010), with the coldest winter in 2005, which induced a shift in the North Atlantic heat budget and circulation (Somavilla et al., 2016). These cold winters are associated with more intense baroclinic instabilities inducing vertical velocities at the (sub)mesoscale and an early increase of small-scale variance (November in 2004). In contrast, the years 2006-2008 represent warm winters (with the warmest in 2007), a shallow mixed layer and a weak generation rate of eddy kinetic energy.

Therefore, this experiment shows a straight impact of large-scale ocean-atmosphere heat fluxes on the intensity of (sub)mesoscale activity in a region under coastal influence. This new insight in understanding the (sub)mesoscale in coastal regions, thanks to high-resolution numerical modelling, will contribute understanding of small-scale fluctuations in biogeochemical production.

Data availability. The model configuration and the source codes are available in Thetten et al. (2017). The CORA-IBI dataset is available in Szekely et al. (2017). SEVIRI remotely sensed sea surface temperature data are available at http://www.osi-saf.org/ $1 \mathrm{ml} /$ pres_SST. ASPEX ADCP data are published in Le Boyer et al. (2013). ARCADINO data are published in Batifoulier et al. (2012). 


\section{Appendix A}

In the MARS3D model, the set of primitive equations (Lazure and Dumas, 2008) is obtained based on usual assumptions (Boussinesq and shallow-water assumptions) in a hydrostatic framework. As the model is based on vertical sigma coordinates, equations are rewritten in a sigma coordinate framework, where (Song and Haidvogel, 1994)

$(z=\zeta)$

with $(z=-H)$, where $\sigma$ is the vertical coordinate and $D$ is the height of water column, with $D=H+\zeta . H$ is the depth of the fluid at rest; $\zeta$ is the sea surface elevation. $z$ and $\sigma$ increase upwards. The result is that at the sea surface $(z=\zeta)$ and $\sigma=0$. In contrast, at the sea floor $(z=-H)$ and $\sigma=-1$

We have noted the $L$ operator as

$L(A)=u \frac{\partial A}{\partial x}+v \frac{\partial A}{\partial y}+w \frac{\partial A}{\partial \sigma}$.

$u$ is the zonal velocity, $v$ the meridional velocity and $w$ is the vertical velocity in the sigma coordinate framework $(x, y, \sigma)$ with

$$
\begin{aligned}
w & =\frac{1}{D}\left(w-\sigma \frac{\partial \zeta}{\partial t}-u\left(\sigma \frac{\partial \zeta}{\partial x}+(\sigma-1) \frac{\partial H}{\partial x}\right)\right. \\
& \left.-v\left(\sigma \frac{\partial \zeta}{\partial y}+(\sigma-1) \frac{\partial H}{\partial y}\right)\right) .
\end{aligned}
$$

The set of primitive equations is then in Cartesian coordinates:

$$
\begin{aligned}
& \frac{1}{D} \frac{\partial p}{\partial \sigma}=-\rho g \\
& \frac{\partial u}{\partial t}+L(u)-f v=-g \frac{\partial \zeta}{\partial x}-\frac{1}{\rho_{0}} \frac{\partial P a}{\partial x}+\pi_{x} \\
& +\frac{1}{D} \frac{\partial\left(\frac{n z}{D} \frac{\partial u}{\partial \sigma}\right)}{\partial \sigma}+F_{x} \\
& \frac{\partial v}{\partial t}+L(v)+f u=-g \frac{\partial \zeta}{\partial y}-\frac{1}{\rho_{0}} \frac{\partial P a}{\partial y}+\pi_{y} \\
& +\frac{1}{D} \frac{\partial\left(\frac{n z}{D} \frac{\partial v}{\partial \sigma}\right)}{\partial \sigma}+F_{y} \\
& \frac{\partial \zeta}{\partial t}+\frac{\partial D u}{\partial x}+\frac{\partial D v}{\partial y}+\frac{\partial D w}{\partial \sigma}=0 \\
& \frac{\partial D T}{\partial t}+\frac{\partial D\left(u T-k_{x} \frac{\partial T}{\partial x}\right)}{\partial x}+\frac{\partial D\left(v T-k_{y} \frac{\partial T}{\partial y}\right)}{\partial y} \\
& +\frac{\partial D\left(w T-\frac{k_{z}}{D^{2}} \frac{\partial T}{\partial \sigma}\right)}{\partial \sigma}=\frac{1}{\rho_{0} C_{P}} \frac{\partial I}{\partial \sigma} \\
& \frac{\partial D S}{\partial t}+\frac{\partial D\left(u S-k_{x} \frac{\partial S}{\partial x}\right)}{\partial x}+\frac{\partial D\left(v S-k_{y} \frac{\partial S}{\partial y}\right)}{\partial y} \\
& +\frac{\partial D\left(w S-\frac{k_{z}}{D^{2}} \frac{\partial S}{\partial \sigma}\right)}{\partial \sigma}=0 .
\end{aligned}
$$

The equation of state relates density to salinity, temperature and pressure:

$\rho=F(S, T, p)$,

where $F$ is a non-linear function (not stated explicitly here; Jackett and McDougall, 1995).

From Eq. (1) and introducing the buoyancy $b=$ $-g\left(\rho-\rho_{0}\right) / \rho_{0}$ within a sigma coordinate framework, the zonal and meridian components of the baroclinic pressure gradient $\left(\pi_{x}, \pi_{y}\right)$ are

$$
\begin{aligned}
& \pi_{x}=\frac{\partial}{\partial x}\left[D \int_{\sigma}^{1} b d \sigma\right]+b\left(\sigma \frac{\partial D}{\partial x}-\frac{\partial H}{\partial x}\right) \\
& \pi_{y}=\frac{\partial}{\partial y}\left[D \int_{\sigma}^{1} b d \sigma\right]+b\left(\sigma \frac{\partial D}{\partial y}-\frac{\partial H}{\partial y}\right) .
\end{aligned}
$$

The horizontal friction terms are

$$
\begin{aligned}
F_{x} & =\frac{1}{D} \frac{\partial}{\partial x}\left[D v_{x} \frac{\partial u}{\partial x}\right]+\frac{1}{D} \frac{\partial}{\partial x}\left[v_{x}\left(\frac{\partial H}{\partial x}-\sigma \frac{\partial D}{\partial x}\right) \frac{\partial u}{\partial \sigma}\right] \\
+ & \frac{1}{D} \frac{\partial}{\partial \sigma}\left[v_{x}\left(\frac{\partial H}{\partial x}-\sigma \frac{\partial D}{\partial x}\right) \frac{\partial u}{\partial x}\right] \\
& +\frac{1}{D} \frac{\partial}{\partial \sigma}\left[\frac{v_{x}}{D}\left(\frac{\partial H}{\partial x}-\sigma \frac{\partial D}{\partial x}\right)^{2} \frac{\partial u}{\partial \sigma}\right] \\
F_{y} & =\frac{1}{D} \frac{\partial}{\partial y}\left[D v_{y} \frac{\partial v}{\partial y}\right]+\frac{1}{D} \frac{\partial}{\partial y}\left[v_{y}\left(\frac{\partial H}{\partial y}-\sigma \frac{\partial D}{\partial y}\right) \frac{\partial v}{\partial \sigma}\right] \\
& +\frac{1}{D} \frac{\partial}{\partial \sigma}\left[v_{y}\left(\frac{\partial H}{\partial y}-\sigma \frac{\partial D}{\partial y}\right) \frac{\partial v}{\partial y}\right] \\
& +\frac{1}{D} \frac{\partial}{\partial \sigma}\left[\frac{v_{y}}{D}\left(\frac{\partial H}{\partial y}-\sigma \frac{\partial D}{\partial y}\right)^{2} \frac{\partial v}{\partial \sigma}\right],
\end{aligned}
$$

where $x, y$ and $\sigma$ are the Cartesian coordinates of the framework $u$ (zonal velocity), $v$ (meridian velocity) and $w^{*}$ (vertical velocity), respectively; $H(x, y)$ is absolute value of bottom position; $S, T$ and $p$ are, respectively, salinity, temperature and pressure.

$f=2 \Omega \sin \varphi$ is the Coriolis parameter, $\Omega=$ $2 \pi / 86164 \mathrm{rads}^{-1}$ Earth's rotation frequency, $g$ gravity, $b=-g\left(\rho-\rho_{0}\right) / \rho_{0}$ buoyancy, $\rho=\rho(S, T, p)$ seawater density, $\rho_{0}$ reference density, $C_{p}$ sea water heat capacity, $I$ shortwave heat fluxes, $n z$ vertical eddy viscosity, $k z$ vertical eddy diffusivity, $v_{x}$ and $v_{y}$ horizontal eddy viscosity, $k_{x}$ and $k_{y}$ horizontal eddy diffusivity. 
The boundary conditions are expressed as

Boundary conditions at Boundary conditions at the surface $\sigma=0$ the bottom $\sigma=-1$

$\begin{array}{ll}\frac{n z}{D} \frac{\partial u}{\partial \sigma}=\frac{\tau_{s x}}{\rho_{0}} & \frac{n z}{D} \frac{\partial u}{\partial \sigma}=\frac{\tau_{b x}}{\rho_{0}} \\ \frac{n z}{D} \frac{\partial v}{\partial \sigma}=\frac{\ell_{s y}}{\rho_{0}} & \frac{n z}{D} \frac{\partial u}{\partial \sigma}=\frac{\ell_{b y}}{\rho_{0}} \\ \frac{k z}{D} \frac{\partial T}{\partial \sigma}=\frac{Q_{T}}{\rho_{0} C_{p}} & k z \frac{\partial T}{\partial \sigma}=0 \\ k z \frac{\partial S}{\partial \sigma}=0 & k z \frac{\partial S}{\partial \sigma}=0 \\ w^{*}=0 & w^{*}=0\end{array}$

where $Q_{T}$ is the heat flux at the air-sea interface, $\left(\tau_{\mathrm{s} x}, \tau_{\mathrm{s} y}\right)=\rho_{\mathrm{a}} C d_{\mathrm{s}}\|\boldsymbol{W}\|\left(W_{x}, W_{y}\right)$ are the surface stress components with

$\rho_{\mathrm{a}}=1.25 \mathrm{~kg} \mathrm{~m}^{-3} C d_{\mathrm{S}}=0.016$,

where $\left(W_{x}, W_{y}\right)$ is the wind velocity vector at $10 \mathrm{~m}$ above the sea surface.

$\left(\tau_{\mathrm{b} x}, \tau_{\mathrm{b} y}\right)=\rho_{0} C d_{\mathrm{B}}\|\boldsymbol{u}\|(u, v)$ are the bottom stress components with

$C d_{\mathrm{B}}=\left(\frac{\kappa}{\ln \left(\frac{z+H+z_{0}}{z_{0}}\right)}\right)^{2}$,

where $\kappa$ refers to the Von Karman constant and $z_{0}$ the bed roughness. 
Competing interests. The authors declare that they have no conflict of interest.

Acknowledgements. This study is part of the LEFE/GMMC project ENIGME. Model experiments have been performed with one of the GENCI (French Big National Equipment Intensive Computing) computational resources administered at CINES (National Computing Center for Higher Education). The computing time of this study costs 3.6 million core hours. We would like to thank Arnaud Le Boyer and Pascal Lazure for providing ASPEX data. Remotely sensed sea surface temperature data are provided by OSI-SAF (http://www.osi-saf.org/) and belong to EUMETSAT. Data processing has been performed using the open-source Python library VACUMM. We also thank Bernard Le Cann, Louis Marié and Christophe Maes for the insightful discussions. Special thanks are given to Liam Brannigan and an anonymous reviewer for their very constructive comments.

Edited by: A. J. George Nurser

Reviewed by: Liam Brannigan and one anonymous referee

\section{References}

Agoumi, A.: Modélisation du régime thermique de la Manche, Manche, PhD Thesis, Ecole Nationale des Ponts et Chaussées, https://pastel.archives-ouvertes.fr/tel-00523011, 255 pp., 1982.

André, X., Le Reste, S., and Rolin, J.-F.: Arvor-C: A Coastal Autonomous Profiling Float, Sea Technol., 51, 10-13, 2010.

Argo: Argo float data and metadata from Global Data Assembly Centre (Argo GDAC), SEANOE, https://doi.org/10.17882/42182, 2000.

Batifoulier F., Lazure P., and Bonneton P.: Poleward coastal jets induced by westerlies in the Bay of Biscay, J. Geophys. Res., 117, C03023, https://doi.org/10.1029/2011JC007658, 2012.

Berger, H., Dumas, F., Petton, S., and Lazure, P.: Evaluation of the hydrology and dynamics of the operational mars3d configuration of the Bay of Biscay, Mercator Ocean - Quartely Newsletter, 49, 60-68, 2014.

Berrisford, P., Dee, D. P., Poli, P., Brugge, R., Fielding, K., Fuentes, M., Kållberg, P. W., Kobayashi, S., Uppala, S., and Simmons, A.: The ERA-Interim archive Version 2.0, ERA Report Series 1, ECMWF, Shinfield Park, Reading, UK, 2011.

Boccaletti, G., Ferrari, R., and Fox-Kemper, B.: Mixed layer instabilities and restratification, J. Phys. Oceanogr., 37, 2228-2250, https://doi.org/10.1175/JPO3101.1, 2007.

Brannigan, L., Marshall, D. P., Naveira-Garabato, A., and Nurser, A. G.: The seasonal cycle of submesoscale flows, Ocean Model., 92, 69-84, 2015.

Caballero, A., Pascual, A., Dibarboure, G., and Espino, M.: Sea level and Eddy Kinetic Energy variability in the Bay of Biscay, inferred from satellite altimeter, J. Mar. Syst., 72, 116-134, https://doi.org/10.1016/j.jmarsys.2007.03.011, 2008.

Caballero, A., Rubio, A., Ruiz, S., Le Cann, B., Testor, P., Mader, J., and Hernández, C.: South-Eastern Bay of Biscay eddy-induced anomalies and their effect on chlorophyll distribution, J. Mar. Syst., 162, 57-72, https://doi.org/10.1016/j.jmarsys.2016.04.001, 2016.
Callies, J., Ferrari, R., Klymak, J. M., and Gula, J.: Seasonality in submesoscale turbulence, Nat. Commun., 6, 6862, https://doi.org/10.1038/ncomms7862, 2015.

Capet, X., Campos, E. J., and Paiva, A. M.: Submesoscale activity over the Argentinian shelf, Geophys. Res. Lett., 35, 2008a.

Capet, X., McWilliams, J. C., Molemaker, M. J., and Shchepetkin, A. F.: Mesoscale to Submesoscale Transition in the California Current System, Part I: Flow Structure, Eddy Flux, and Observational Tests, J. Phys. Oceanogr., 38, 29-43, https://doi.org/10.1175/2007JPO3671.1, 2008b.

Capet, X., McWilliams, J. C., Molemaker, M. J., and Shchepetkin, A. F.: Mesoscale to Submesoscale Transition in the California Current System, Part II: Frontal Processes, J. Phys. Oceanogr., 38, 44-64, https://doi.org/10.1175/2007JPO3672.1, 2008c.

Charria, G., Lazure, P., Le Cann, B., Serpette, A., Reverdin, G., Louazel, S., Batifoulier, F., Dumas, F., Pichon, A., and Morel, Y.: Surface layer circulation derived from Lagrangian drifters in the Bay of Biscay, J. Mar. Syst., 109/110, S60-S76, https://doi.org/10.1016/j.jmarsys.2011.09.015, 2013.

Chelton, D. B., Deszoeke, R. A., Schlax, M. G., El Naggar, K., and Siwertz, N.: Geographical variability of the first baroclinic Rossby radius of deformation, J. Phys. Oceanogr., 28, 433-460, 1998.

Costoya, X., deCastro, M., Gómez-Gesteira, M., and Santos, F.: Mixed Layer Depth Trends in the Bay of Biscay over the Period 1975-2010, PLoS ONE, 9, e99321, https://doi.org/10.1371/journal.pone.0099321, 2014.

de Boyer Montégut, C., Madec, G., Fischer, A. S., Lazar, A., and Iudicone, D.: Mixed layer depth over the global ocean: An examination of profile data and a profilebased climatology, J. Geophys. Res.-Ocean., 109, C12003, https://doi.org/10.1029/2004JC002378, 2004.

Duhaut, T., Honnorat, M., and Debreu, L.: Développements numériques pour le modele MARS, PREVIMER report-Ref: 06/2 $210290,2008$.

Duhaut, T. H. A. and Straub, D. N.: Wind stress dependence on ocean surface velocity: implications for mechanical energy input to ocean circulation, J. Phys. Ocean., 36, 202-211, 2006.

Dumousseaud, C., Achterberg, E. P., Tyrrell, T., Charalampopoulou, A., Schuster, U., Hartman, M., and Hydes, D. J.: Contrasting effects of temperature and winter mixing on the seasonal and inter-annual variability of the carbonate system in the Northeast Atlantic Ocean, Biogeosciences, 7, 1481-1492, https://doi.org/10.5194/bg-7-1481-2010, 2010.

Dussurget, R., Birol, F., Morrow, R., and De Mey, P.: Fine Resolution Altimetry Data for a Regional Application in the Bay of Biscay, Mar. Geod., 34, 447-476, https://doi.org/10.1080/01490419.2011.584835, 2011.

Elipot, S. and Gille, S. T.: Estimates of wind energy input to the Ekman layer in the Southern Ocean from surface drifter data, J. Geophys. Res., 114, C06003, https://doi.org/10.1029/2008JC005170, 2009.

Ferrari, R.: A frontal challenge for climate models, Science, 332, 316-317, 2011.

Fox-Kemper, B., Ferrari, R., and Halberg, R.: Parameterization of Mixed Layer Eddies, Part I: Theory and Diagnosis, J. Phys. Oceanogr., 38, 1145-1165, https://doi.org/10.1175/2007JPO3792.1, 2008a. 
Fox-Kemper, B., Ferrari, R., and Halberg, R.: Parameterization of Mixed Layer Eddies, Part II: Prognosis and Impact, J. Phys. Oceanogr., 38, 1166-1179, https://doi.org/10.1175/2007JPO3788.1, 2008b.

Gill, A. E.: Atmospheric-Ocean Dynamics, Academic Pres, 1982.

Haidvogel, D. B. and Beckmann A.: Numerical Ocean Circulation Modeling. Imperial College Press, 1999.

Hartman, S. E., Hartman, M. C., Hydes, D. J., Jiang, Z.-P., Smythe-Wright, D., and González-Pola, C.: Seasonal and interannual variability in nutrient supply in relation to mixing in the Bay of Biscay, Deep-Sea Res. Pt. II, 106, 68-75, https://doi.org/10.1016/j.dsr2.2013.09.032, 2014.

Huang, R. X., Wang, W., and Liu, L. L.: Decadal variability of windenergy input to the world ocean, Deep-Sea Res. Pt. II, 53, 31-41, 2006.

Jackett, D. R. and McDougall, T. J.: Minimal Adjustment of Hydrostatic Profiles to Achieve Static Stability, J. Atmos. Ocean. Tech., 12, 381-389, 1995.

Kersalé, M., Marié, L., Le Cann, B., Serpette, A., Lathuilière, C., Le Boyer, A., Rubio, A., and Lazure, P.: Poleward along-shore current pulses on the inner shelf of the Bay of Biscay. Estuarine, Coast. Shelf Sci., 179, 155-171, https://doi.org/10.1016/j.ecss.2015.11.018, 2015.

Klein, P., Lapeyre, G., Capet, X., Le Gentil, S., and Sasaki, H.: Upper Ocean Turbulence from High-Resolution 3D Simulations, J. Phys. Oceanogr., 38, 1748-1763, https://doi.org/10.1175/2007JPO3773.1, 2008.

Kolmogorov, A.: Dissipation of energy in the locally isotropic turbulence, Proceedings mathematical and physical sciences, The Royal Society, London, 1941.

Lazure P. and Dumas F.: An external-internal mode coupling for a 3D hydrodynamical model for applications at regional scale (MARS), Adv. Water Resour., 31, 233-250, https://doi.org/10.1016/j.advwatres.2007.06.010, 2008.

Lazure, P., Garnier, V., Dumas, F., Herry, C., and Chifflet, M.: Development of a hydrodynamic model of the Bay of Biscay, Validation of hydrology, Cont. Shelf Res., 29, 985-997, https://doi.org/10.1016/j.csr.2008.12.017, 2009.

Le Boyer, A., Charria, G., Le Cann, B., Lazure, P., and Marié, L.: Circulation on the shelf and the upper slope of the Bay of Biscay, Cont. Shelf Res., 55, 97-107, https://doi.org/10.1016/j.csr.2013.01.006, 2013.

Luterbacher, J., Liniger, M. A., Menzel, A., Estrella, N., DellaMarta, P. M., Pfister, C., Rutishauser, T., and Xoplaki, E.: Exceptional European warmth of autumn 2006 and winter 2007: historical context, the underlying dynamics, and its phonological impacts, Geophys. Res. Lett., 34, L12704, https://doi.org/10.1029/2007GL029951, 2007.

Lyard, F., Lefevre, F., Letellier, T., and Francis, O.: Modelling the global ocean tides: modern insights from FES2004, Ocean Dynam., 56, 394-415, https://doi.org/10.1007/s10236-006-0086-x, 2006.

Marchesiello, P., McWilliams, J. C., and Shchepetkin, A.: Open boundary conditions for long-term integration of regional oceanic models, Ocean Model., 3, 1-20, 2001.

McWilliams, J. C.: Submesoscale, coherent vortices, Rev. Geophys., 23, 165-182, https://doi.org/10.1029/RG023i002p00165, 1985.
Mesinger, F. and Arakawa, A.: Numerical methods used in atmospheric models, GARP Publications Series, No. 17, World Meteorological Organization, 1976.

Molemaker, M. J., McWilliams, J. C., and Dewar, W. K.: Submesoscale Instability and Generation of Mesoscale Anticyclones near a Separation of the California Undercurrent, J. Phys. Oceanogr., 45, 613-629, https://doi.org/10.1175/JPO-D13-0225.1, 2015.

Molines, J. M., Barnier, B., Penduff, T., Treguier, A. M., and Le Sommer, J.: ORCA12.L46 climatological and interannual simulations forced with DFS4.4: GJM02 and MJM88, Drakkar Group Experiment report GDRI-DRAKKAR-2014-03-19, 2014.

Pasquet, A., Szekely, T., and Morel, Y.: Production and dispersion of mixed waters in stratified coastal areas, Cont. Shelf Res., 39, 49-77, 2012.

Pingree, R. D. and Le Cann, B.: Anticyclonic eddy X91 in the southern Bay of Biscay, May 1991 to February 1992, J. Geophys. Res., 97, 14353-14367, https://doi.org/10.1029/92JC01181, 1992a.

Pingree, R. D. and Le Cann, B.: Three anticyclonic Slope Water Oceanic eDDIES (SWODDIES) in the Southern Bay of Biscay in 1990, Deep-Sea Res. Pt. A, 39, 1147-1175, 1992b.

Pingree, R. D., Sinha, B., and Griffiths, C. R.: Seasonality of the European slope current (Goban Spur) and ocean margin exchange, Cont. Shelf Res., 19, 929-975, https://doi.org/10.1016/S02784343(98)00116-2, 1999.

Porter, M., Inall, M. E., Green, J. A. M., Simpson, J. H., Dale, A. C., and Miller, P. I: Drifter observations in the summer time Bay of Biscay slope current, J. Mar. Syst., 157, 65-74, https://doi.org/10.1016/j.jmarsys.2016.01.002, 2016.

Renaudie, C., Morel, Y., Hello, G., Giordani, H., and Baraille, R.: Observation and analysis of mixing in a tidal and wind-mixed coastal region, Ocean Model., 37, 65-84, 2011.

Reverdin, G., Marié, L., Lazure, P., d'Ovidio, F., Boutin, J., Testor, P., Martin, N., Lourenco, A., Gaillard, F., Lavin, A., Rodriguez, C., Somavilla, R., Mader, J., Rubio, A., Blouch, P., Rolland, J., Bozec, Y., Charria, G., Batifoulier, F., Dumas, F., Louazel, S., and Chanut, J.: Freshwater from the Bay of Biscay shelves in 2009, J. Mar. Syst., 109/110, Supplement S134-S143, https://doi.org/10.1016/j.jmarsys.2011.09.017, 2013.

Rodi, W. and Mansour, N. N.: Low Reynolds number $k-\varepsilon$ modelling with the aid of direct simulation data, J. Fluid Mechan., 250, 509-529, https://doi.org/10.1017/S0022112093001545, 1993.

Rodi, W.: Turbulence Models and Their Application in Hydraulics: A State-of-the-Art Review, 3rd Edn., IAHR Monograph, Balkema,Rotterdam, Netherlands, 1993.

Sasaki, H., Klein, P., Qiu, B., and Sasai, Y.: Impact of oceanic-scale interactions on the seasonal modulation of ocean dynamics by the atmosphere, Nat. Commun., 5, 5636, https://doi.org/10.1038/ncomms6636, 2014.

Solabarrieta, L., Rubio, A., Castanedo, S., Medina, R., Charria, G., and Hernández, C.: Surface water circulation patterns in the southeastern Bay of Biscay: New evidences from HF radar data, Cont. Shelf Res., 74, 60-76, 2014.

Somavilla, R., González-Pola, C., Rodriguez, C., Josey, S. A., Sánchez, R. F., and Lavín, A.: Large changes in the hydrographic structure of the Bay of Biscay after the extreme mixing of winter 2005, J. Geophys. Res., 114, C01001, https://doi.org/10.1029/2008JC004974, 2009. 
Somavilla, R., González-Pola, C., Ruiz-Villarreal, M., and Montero, A. L.: Mixed layer depth (MLD) variability in the southern Bay of Biscay, Deepening of winter MLDs concurrent with generalized upper water warming trends?, Ocean Dynam., 61, 1215, https://doi.org/10.1007/s10236-011-0407-6, 2011.

Somavilla, R., González-Pola, C., Schauer, U., and Budéus, G.: Mid-2000s North Atlantic shift: Heat budget and circulation changes, Geophys. Res. Lett., 43, 2059-2068, https://doi.org/10.1002/2015GL067254, 2016.

Song, Y. and Haidvogel, D. B.: A semi-implicit ocean circulation model using a generalized topography-following coordinate system, J. Comp. Phys., 115, 228-244, 1994.

Soufflet, Y., Marchesiello, P., Lemarié, F., Jouanno, J., Capet, X., Debreu, L., and Benshila, R.: On effective resolution in ocean models, Ocean Model., 98, 36-50, https://doi.org/10.1016/j.ocemod.2015.12.004, 2016.

Szekely, T., Bezaud, M., Pouliquen, S., Reverdin, G., and Charria, G.: CORA-IBI, Coriolis Ocean Dataset for Reanalysis for the Ireland-Biscay-Iberia region, SEANOE, https://doi.org/10.17882/50360, 2017.
Theetten, S., Vandermeirsch, F., and Charria, G.: BACH1000_100lev-51 : a MARS3D model configuration for the Bay of Biscay, SEANOE, https://doi.org/10.17882/43017, 2017.

Thompson, A. F., Lazar, A., Buckingham, C., Naveira Garabato, A. C., Damerell, G. M., and Heywood, K. J.: Open-ocean submesoscale motions: A full seasonal cycle of mixed layer instabilities from gliders, J. Phys. Oceanogr., 46, 1285-1307, 2016.

Tulloch, R., Marshall, J., Hill, C., and Smith, K. S.: Scales, Growth Rates, and Spectral Fluxes of Baroclinic Instability in the Ocean, J. Phys. Oceanogr., 41, 1057-1076, https://doi.org/10.1175/2011JPO4404.1, 2011.

van Aken, H. M.: Surface currents in the Bay of Biscay as observed with drifters between 1995 and 1999, Deep-Sea Res. Pt. I, 49, 1071-1086, 2002. 